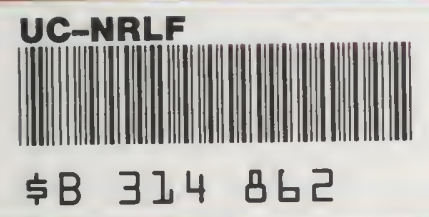

THE PHYSICAL PROPERTIES OF SOILS

ARTHUR G. MCCALL 

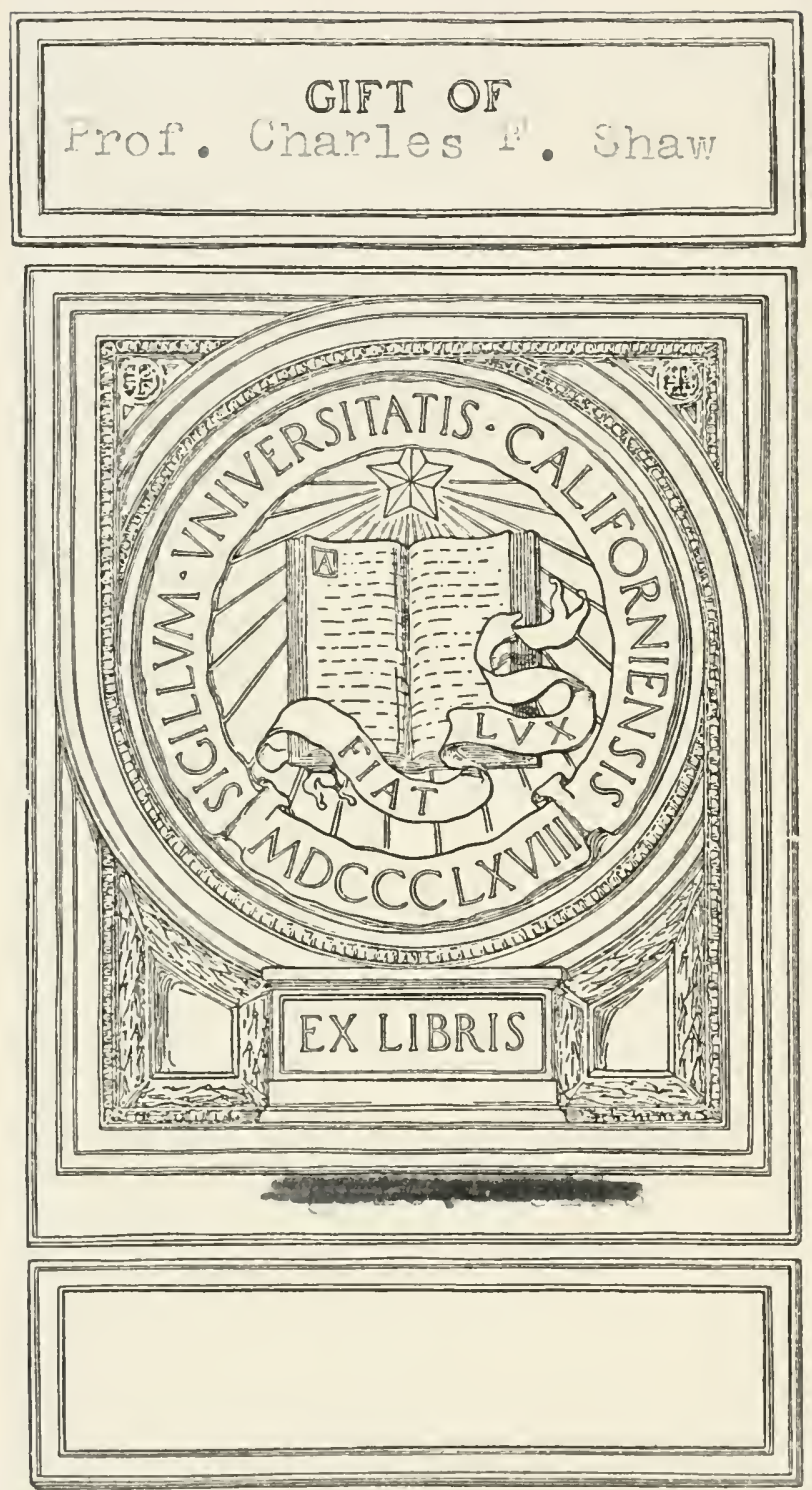
flor. If. Acer 


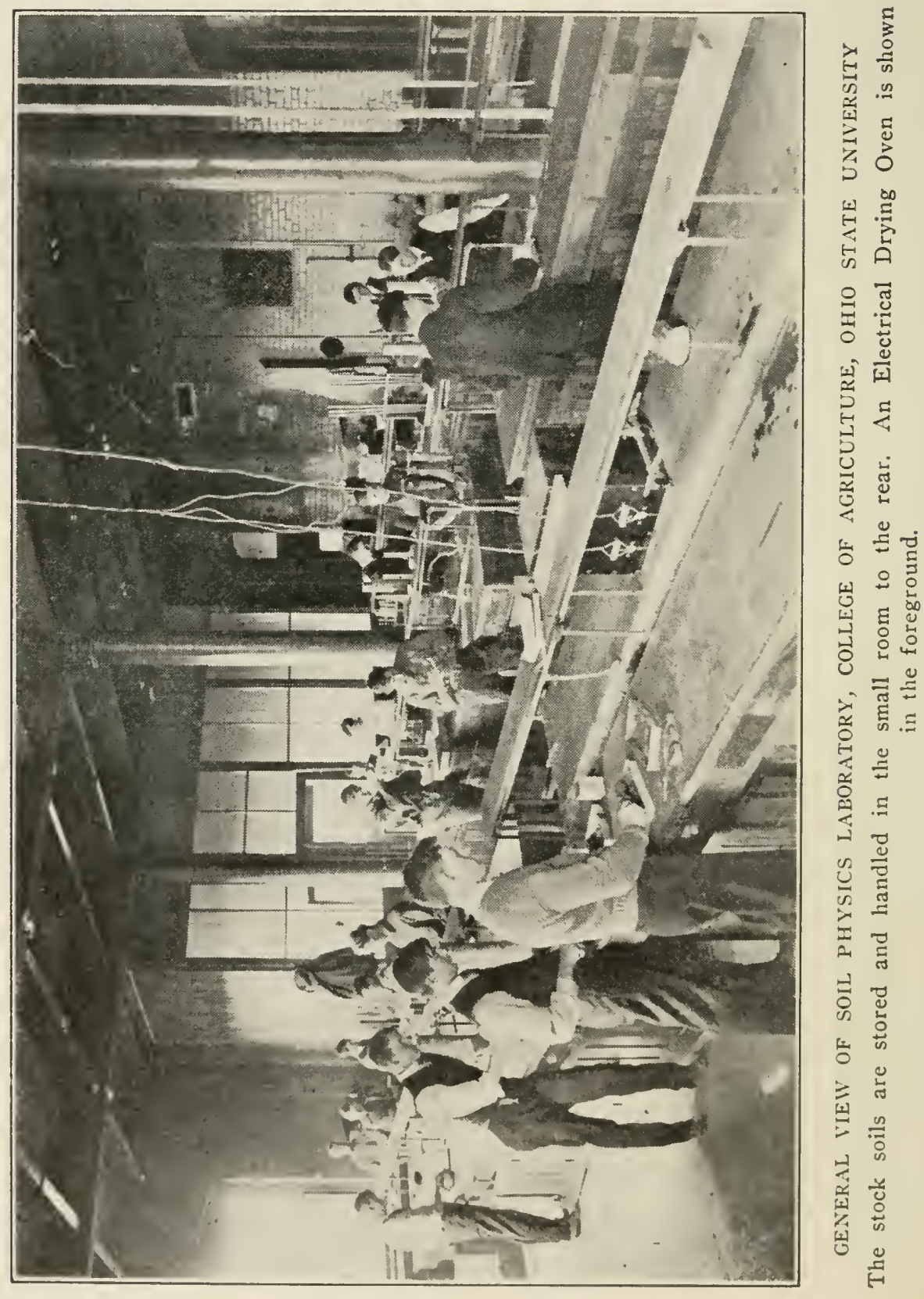




\title{
THE PHYSICAL \\ PROPERTIES OF SOILS
}

\section{A LABORATORY GUIDE}

\author{
By \\ ARTHUR G. McCALL
}

Professor of Agronomy in the College of Agriculture of the

Ohio State University

ILLUSTRATED

NEW YORK

ORANGE JUDD COMPANY

LONDON.

KEGAN PAUL, TRENCH, TRÜBNER \& CO., Limited 1909 
5,593
$M, 503$

CoPyright, 1909

BY

ORANGE JUDD COMPANY

All Rights Reserved

[Entered at Stationers' Hall, London, England]

GIET OF El when d F Shaw

cones soils
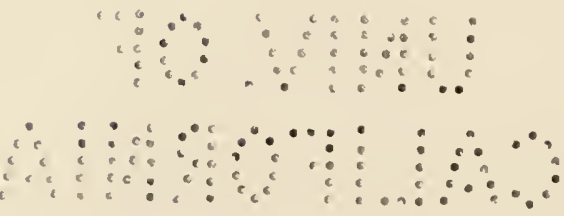


\section{P R E F A C E}

THE experiments described on the following pages are designed especially for the use of the students in the four-year course in agriculture in colleges and universities.

These exercises will give sufficient work to cover two or three terms, depending upon the number of hours devoted to laboratory practice each week. An effort has been made to outline the experiments as clearly and concisely as possible, in order that the student may take up each exercise without delay.

While these practices are the outcome of several years' experience in teaching Soil Physics at the Ohio State University, they are not all original with the author. Material has been drawn from various sources, and so arranged that it may be adapted to instruction in soils under a wide range of conditions.

Acknowledgment is due my assistant, Mr. G. R. Hyslop, for valuable suggestions and aid in working out these practices, and to the following for material and suggestions, Prof. M. F. Miller, University of Missouri, Prof. E. O. Fippin, Cornell University, Dr. L. J. Briggs, U. S. Dept. of Agriculture, Professors Stevenson and Schaub of Iowa State College, and others.
A. G. McCall.

Soil Physics Laboratory

Ohio State Unizersity.

Columbus, Ohio.

August, 1908. 
Digitized by the Internet Archive in 2008 with funding from Microsoft Corporation 


\section{CONTENTS}

PAGE

General Information . . . . . . . . . I

Soils Laboratory Desk Outfit • . . . . . 3

Stock Soils . . . . . . . . . . 5

千 Determination of Hygroscopic Moisture . . . Io

$\nmid$ Determination of Moisture in Field Soils . . . I2

× Determination of the Specific Gravity of Soils . I8

+ Determination of Volume Weight and Pore Space 22

Determination of Pore Space in Field Soils . . 26

Percolation of Water Through Soils . . . . 32

+ Water-holding Capacity of Soils . . . . 38

The Distribution of Capillary Water in Soil

Columns . . . . . . . . . 40

Flow of Air Through Soils . . . . . . . 42

Flow of Air Through Field Soils . . . . . 44

+Capillary Rise of Moisture . . . . . . . 46

Interruption of the Capillary Rise of Moisture . $46^{--}$

Continuous Rise of Capillary Moisture . . . 50

Lateral Movement of Capillary Moisture . . 54

Co-efficient of Evaporation . . . . . . 56

× Effect of Mulches upon Rate of Evaporation . 60

The Absorptive Power of Soils . . . . . 64

The Flocculating Effect of Lime . . . . . 68 
Power of Soils to Retain Fertilizers in Solution . 70 The Specific Heat of Soils . . . . . . 74 Mechanical Analysis of Soils . . . . . . So Chromic Acid Method of Determining Organic Matter . . . . . . . . . . 92 Directions for Taking Soil Samples . . . . 96 Standardization of the Eye-piece Micrometer . 99 Table of Data . . . . . . . . . . . I00 Index . . . . . . . . . . . . . IOI 


\section{The Physical Properties of Soils}

\section{GENERAL INFORMATION AND DIRECTIONS}

The laboratory instruction in soils is confined almost exclusively to a study of the physical properties of soils and the relation of these properties to rational methods of soil management.

The relation of the soil to moisture being of first importance, a great many of these experiments are designed to show the influence of physical conditions upon the movement and retention of moisture in the soil.

There are various ways of expressing the amount of water present in a soil: (I) as per cent of dry weight of the soil, (2) as per cent of wet weight, (3) as pounds per cubic foot, and (4) as surface inches.

The water content is usually expressed either as per cent of dry weight or as pounds per cubic foot.

The degree of compactness of soils has a great influence upon their behavior, hence for all comparative tests it is very necessary that all the soils be compacted uniformly. For this purpose specially designed compacting machines are used.

Before beginning an experiment read carefully the entire exercise and see that all the necessary apparatus is at hand. 
The character( $T$ ) following the name of a piece of apparatus means that it must be obtained from the instructor.

At the close of each experiment all apparatus must be cleaned thoroughly and returned to its proper place before credit is given for the work. Full notes on each exercise must be made at the time the experiment is performed. The final report must be made on the blank pages in this book, and should contain (I) a description of the experiment and apparatus used, (2) the results in a neat tabulated form, so that their story can be quickly read, and (3) a short discussion along the lines indicated on the direction sheet.

The references given at the close of the exercises are to be read before the experiment is written up. All books to which reference is made will be kept on a table in the laboratory or adjoining room, where they will be accessible to the students during laboratory hours.

Write your name and the hours during which you are due in the laboratory on the card attached to your desk.

This book is not to be taken from the laboratory except by special permission, but must be left in the place designated by the instructor. 


\section{SOILS LABORATORY DESK OUTFIT}

THE FOLLOWING ARTIClES ARE LOANED TO THIE STUDENT

6 Aluminum Dishes, 3 in.

I Bunsen Burner

I Ring Stand with 3 Rings

I Tongs, Crucible

I Tripod

2 Porcelain Cups

I Spatula

I Test Tube Rack

2 Sets Beakers, I to 5

6 Dishes, Porcelain No. o

+ I Desiccator, 8 in.

X 2 Cylinders, Graduated $250 \mathrm{cc}$.

) 6 Test Tubes

4 Percolators, Oldberg's Cylindrical, 500 cc.

THE FOLLOWING ARTICLES ARE CHARGED TO EACH STUDENT AND CAN NOT BE RETURNED

I Clay Triangle $\$ .05$

I Wire Gauze .05

I Glass Rod .05

3 Ft. Rubber Tubing .15

I Sponge .IO

I Towel .IO

I Test Tube Brush .05

I Box Safety Matches $.0 \mathrm{I}$ 


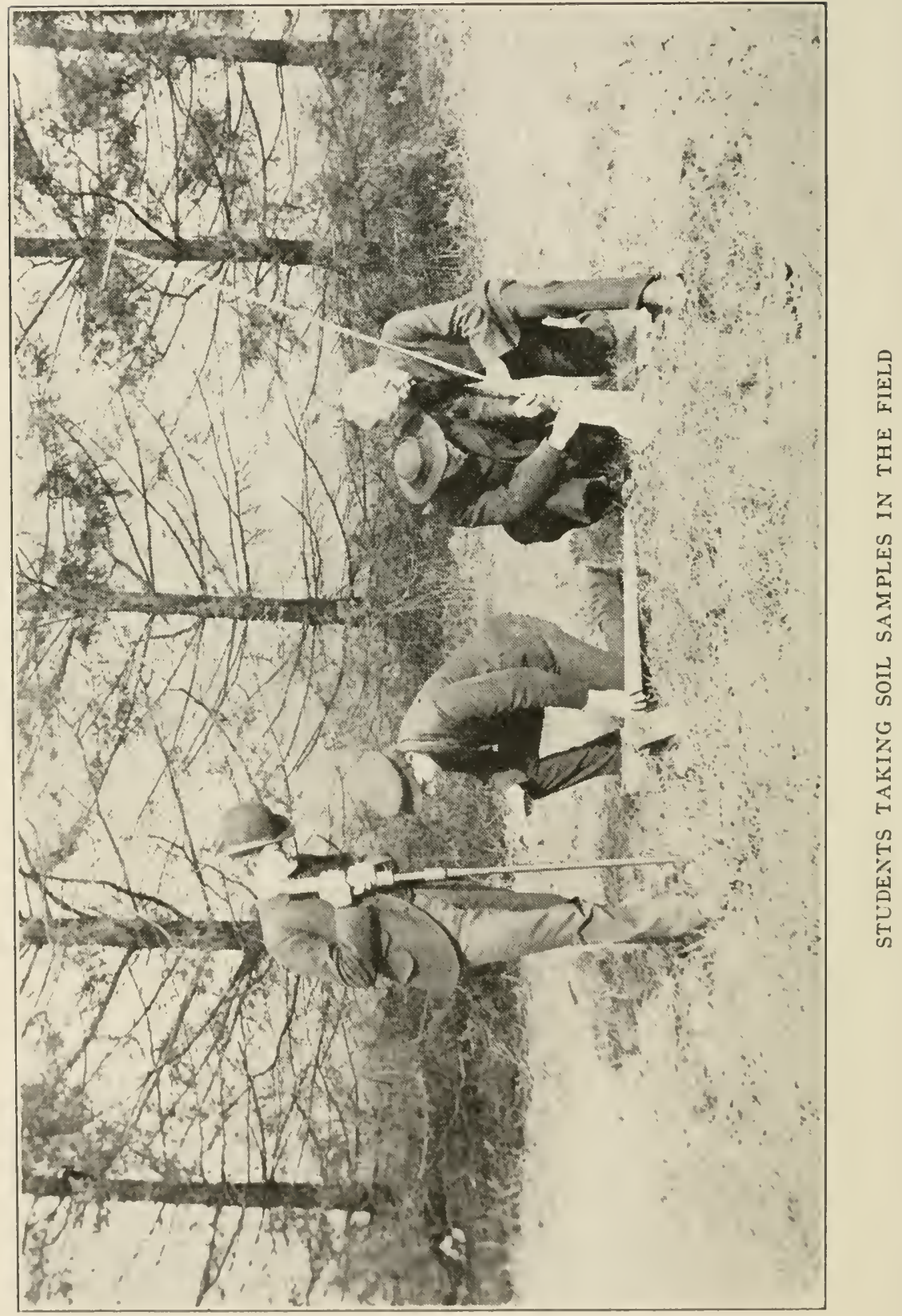




\section{STOCK SOILS}

UNLEss otherwise stated, the soils called for in these exercises will be found in the bins in the soilhandling room opening off from the main laboratory. The soils used consist of (I) sand, (2) sandy loam, (3) loam, or silt, (4) muck, and (5) clay.

I. SAND-clean lake or river sand.

2. SANDY LoAm-a loam with sufficient sand to make open mellow soil.

3. LoAm or Silt-heavier type than No. 2, containing more silt and less sand.

4. Muck-well-drained swamp soil containing a large quantity of organic matter.

5. Clay-a heavy, sticky soil containing a large amount of clay.

The soils are prepared by drying and pulverizing until they pass through a $2 \mathrm{~mm}$. sieve. The different grades of sand are prepared by passing the lake sand through a series of sieves.

The mechanical analysis of each soil is given on the card attached to the bin. These analyses should be recorded on the following page and referred to frequently in interpreting the results obtained in the laboratory. Use the co-ordinate paper to make a graphic representation of the mechanical composition of the soils. 


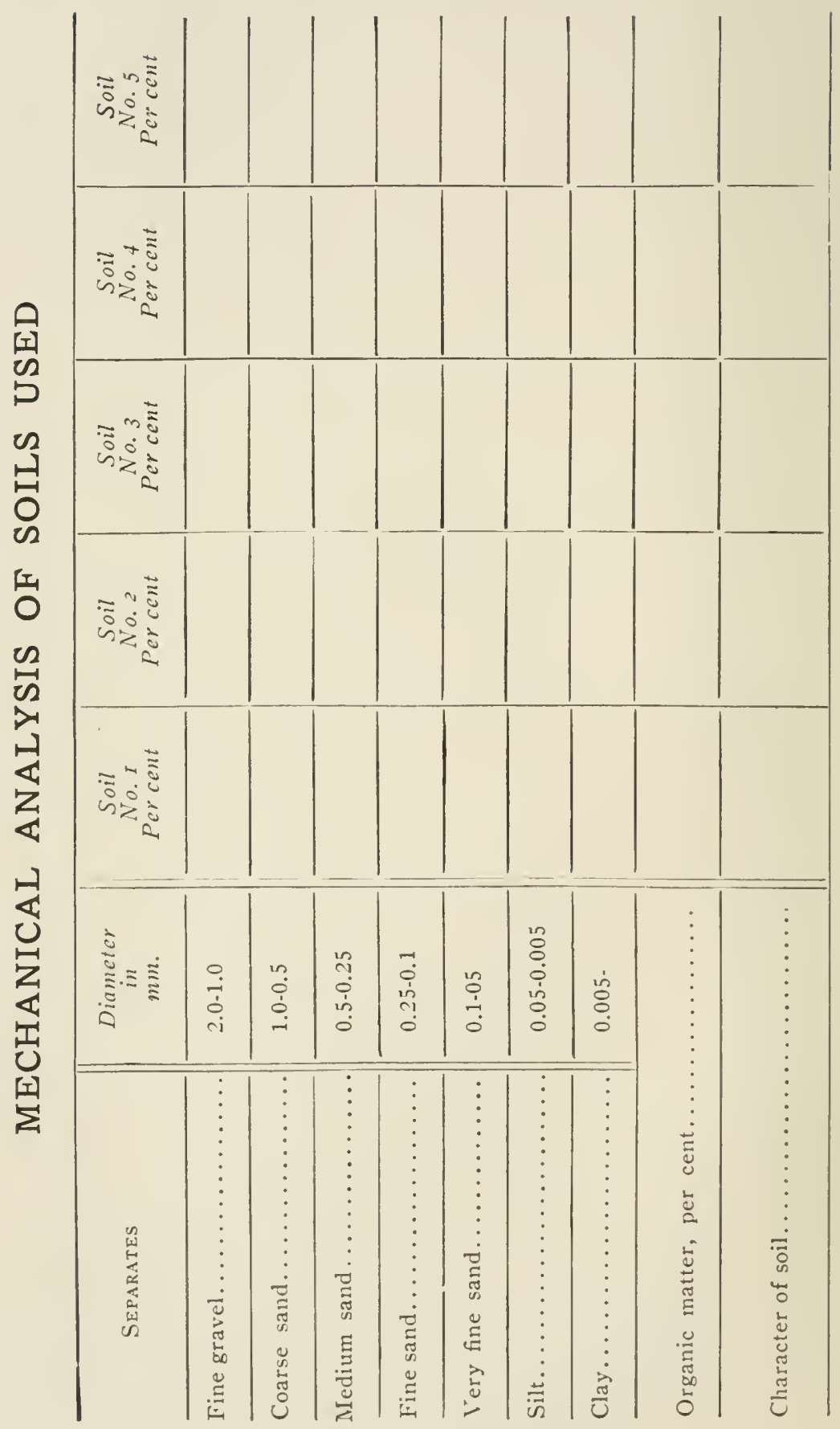


THE PHYSICAL PROPERTIES OF SOHLS

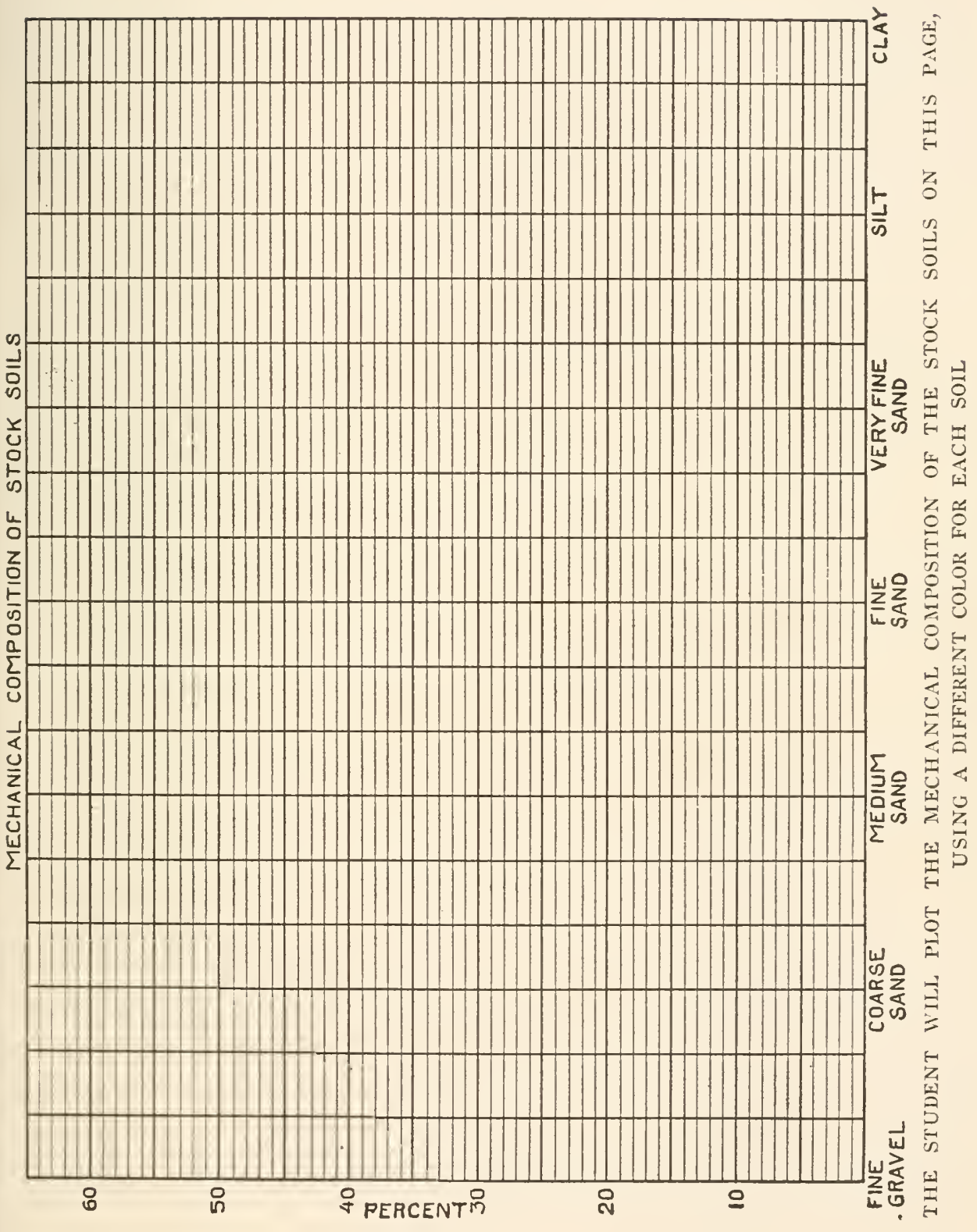




\section{FIRST EXERCISE}

\section{DETERMINATION OF HYGROSCOPIC MOISTURE IN STOCK SOILS}

Determine the hygroscopic moisture of the soil samples in the bins by proceeding as follows:

Carefully weigh a small dish on the chemical balance, then place in the dish a Io-gram representative sample

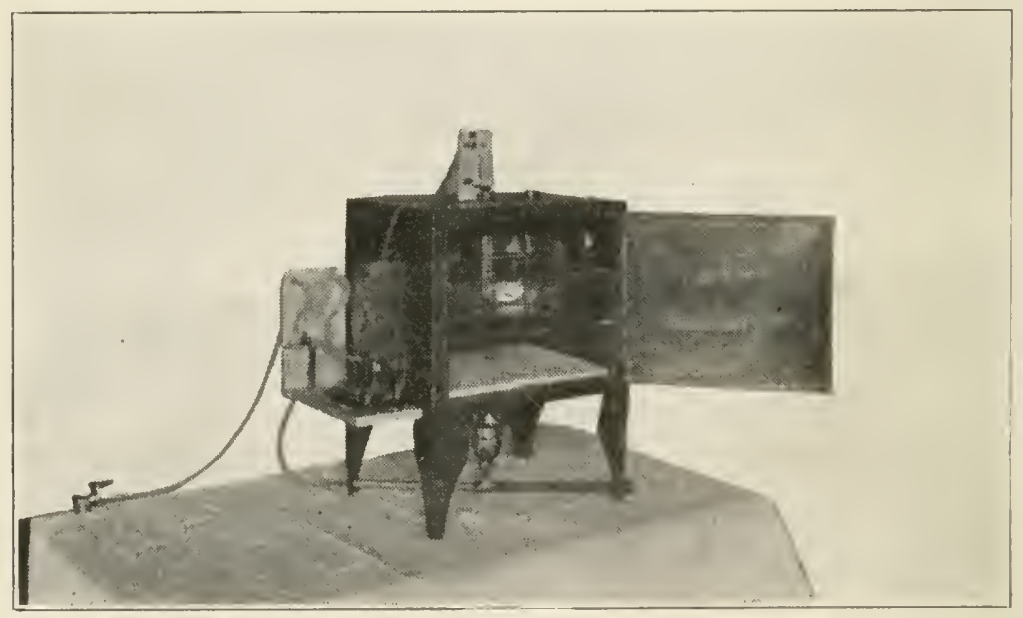

DRYING OVEN HEATED BY GAS

The gas supply is automatically regulated by a relay operated on a battery circuit

of soil. Dry in the oven at $110^{\circ} \mathrm{C}$. for twenty-four hours. The loss in weight is the hygroscopic moisture. The loss in weight divided by the weight of the ovendry soil will give the per cent of hygroscopic moisture.

Although the hygroscopic moisture varies from day to day with the humidity of the atmosphere, these results may be used in subsequent experiments whenever 
STUDENT'S NOTES AND REPORT 


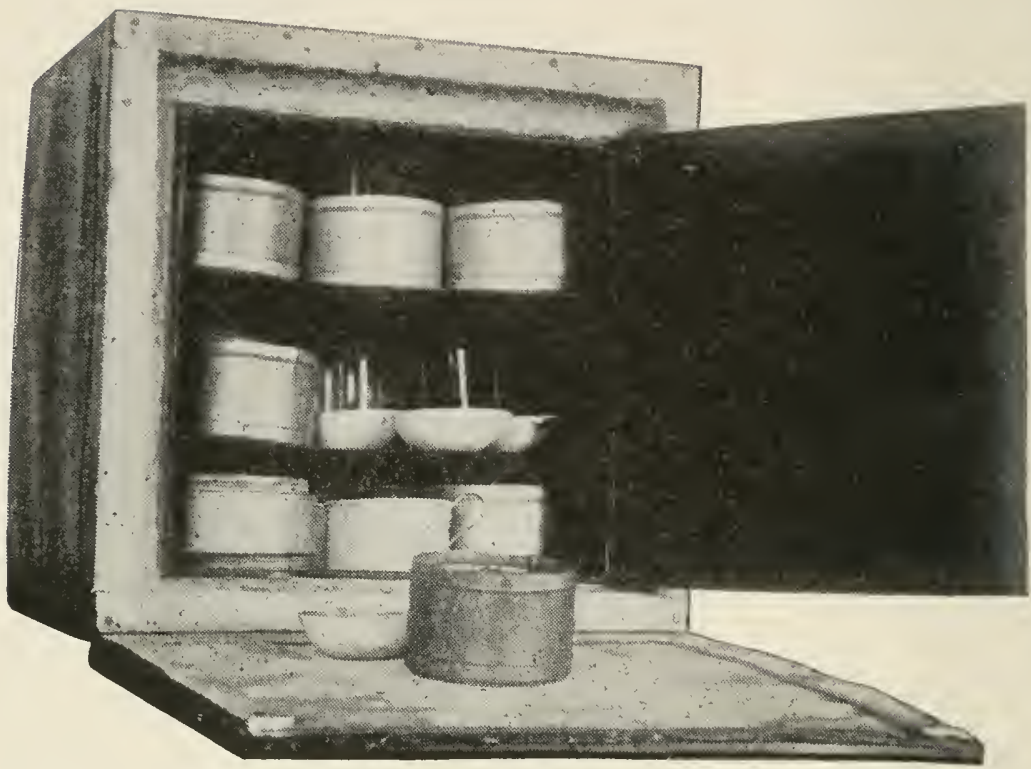

DOUBLE-WALLED DRYING OVEN HEATED BY TWO ELECTRIC-LIGHT BULBS

it is necessary to know the per cent of hygroscopic moisture.

What is the effect of soil texture and the temperature and humidity of the atmosphere upon the hygroscopic moisture?

\section{DETERMINATION OF THE MOISTURE IN FIELD SOILS}

Collect samples in the field from the first, second and third foot of soil under different crop conditions, such as sod land, plowed field and fallow. The samples should come from as small an area as possible in order to have a uniform soil type.

Drive the sampler ( $\mathrm{T}$ ) to the proper depth for each foot, lift from the hole and transfer the soil at once to 
THE PHYSICAL PROPERTIES OF SOILS

STUDENT'S NOTES AND REPORT 
a tight box. Take the samples to the laboratory, weigh each box separately, remove the lid and expose the contents to the air. Weigh at the end of three days

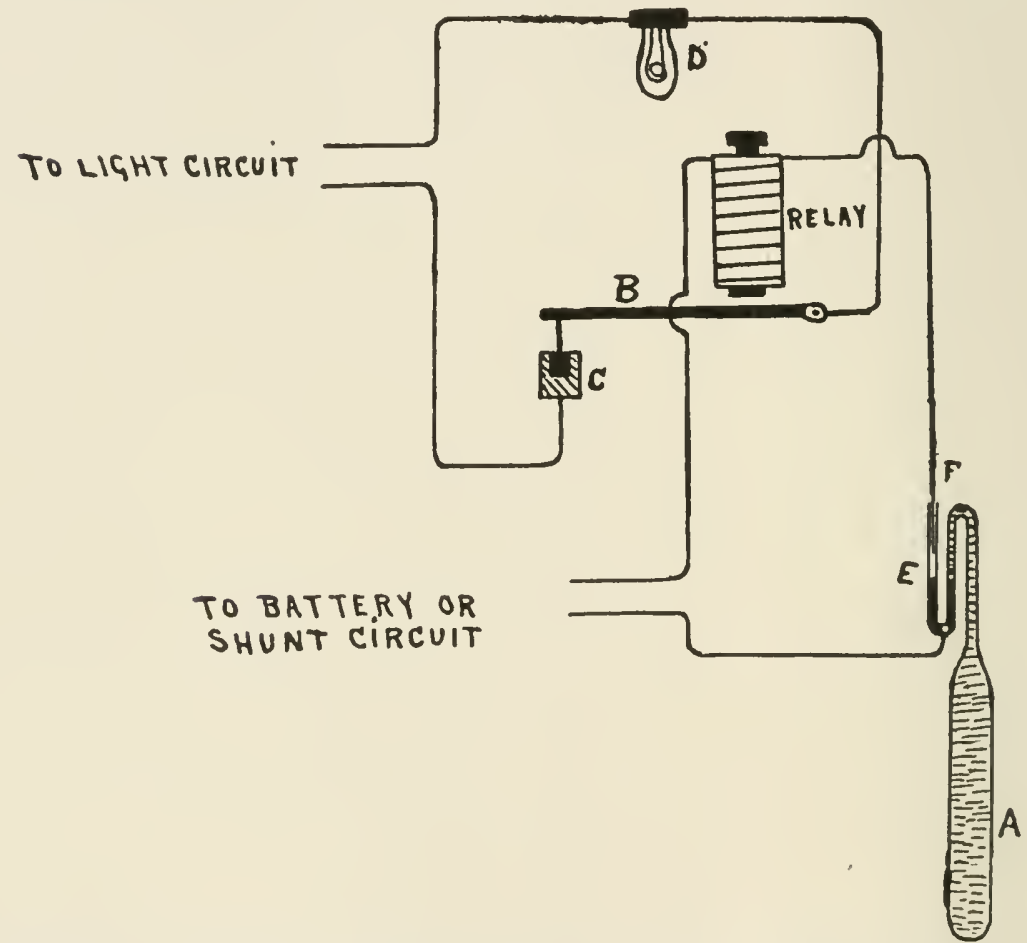

DIAGRAM SHOWING THE CONNECTIONS FOR THE AUTOMATIC CONTROL USED ON ELECTRICAL DRYING OYENS

The Tube $A$ is filled with alcohol or a calcium chloride solution and placed inside the oven. D, the source of heat, is a series of lamps or a coil of fine wire, also located inside the oven. As the temperature increases the liquid in the tube expands. This expansion torces the mercury up in the tube $\mathrm{E}$ until contact is made with the adjustable electrode I: This closes the circuit through the relay, and the armature $B$ is lifted. The heating circuit is broken in the mercury cup at $\mathrm{C}$, and the source of heat at $\mathrm{D}$ is shut off. As the oven cools the mercury at E drops back and the relay circuit is broken, allowing the armature Is to fall and close the heating circuit.

and at twenty-four hour intervals thereafter until approximately constant weight is obtained. The loss in weight is the capillary moisture. Note should be made of the rainfall of the previous week and of the weather conditions at the time the samples were taken. 
THE PHYSICAL PROPERTIES OF SOILS

I 5

STUDENT'S NOTES AND REPORT 
Determine the hygroscopic moisture remainir the air-dry samples, and calculate the moisture wntent of the field samples as follows:

(I) As per cent of the dry weight of the soil.

(2) As pounds per cubic foot.

(3) As surface inches, the total amount to the depth of three feet.

Tabulate the results and compare the moisture content of the soils under the different crop conditions. Discuss the reasons for the observed differences.

ReFerences :

Burkett, "Soils," Chapter IV.

Hall, "The Soil," p. I32.

Bulletin No. 4, Bureau of Soils, pp. 22-24.

Stevenson \& Schaub, "Soil Physics Laboratory

Guide," pp. I-7. 
TIIE PIIYSICAL PROPERTIES OF SOILS

STUDENT'S NOTES AND REPORT 


\section{SECOND EXERCISE}

\section{DETERMINATION OF THE SPECIFIC GRAVITY OF SOILS}

THE specific gravity of soil varies from about 2 up to 2.90 , the average being about 2.65 , which is the specific gravity of quartz crystal. That is, the soil calculated free of air spaces weighs about 2.65 times as much as an equal volume of water. The density will vary with the mineral constituents of the soil and with the amount of organic matter present, the specific gravity decreasing as the organic matter increases.

\section{METHOD OF DETERMINATION}

With specific gravity flasks or pycnometers ( $\mathrm{T}$ ) of $50 \mathrm{cc}$. capacity make duplicate determinations of the specific gravity of soils No. I, No. 4, and No. 5 .

Fill the flask with distilled water and boil for a few minutes in a salt bath to expel the air. Cool the flask to $30^{\circ} \mathrm{C}$., insert the stopper, wipe dry, and when it has cooled to room temperature, weigh. Pour out about half of the water in the flask and introduce into it about ten grams of soil. Again place the flask in the salt bath and boil for a few minutes. Fill the flask with boiled water, cool to $30^{\circ} \mathrm{C}$., stopper and weigh again at room temperature. Transfer the soil to a porcelain dish, evaporate, and dry in the oven to determine accurately the amount of soil used.

\section{CAICULATION}

The weight of the soil used divided by the weight of the water displaced will give the specific gravity of the soil. 
THE PHYSICAL PROPERTIES OF SOILS

STUDENT'S NOTES AND REPORT 
Tabulate the results and use them in connection with the next exercise.

REFERENCE :

Wiley, "Agricultural Analysis," Vol. I., pp. 95-98.

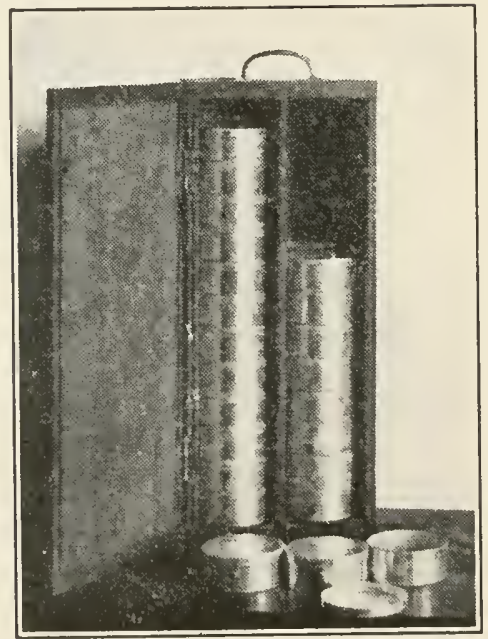

SOIL SAMPLE BOXES W'ITII CARRYING CASE 
STUDENT'S NOTES AND REPORT 
THIRD EXERCISE

\section{DETERMINATION OF VOLUME WEIGHT AND PORE SPACE OF STOCK SOILS}

THE volume weight of a soil is the weight of a given volume. The weight of the soil in grams divided by the volume in cubic centimeters is the density or the apparent specific gravity.

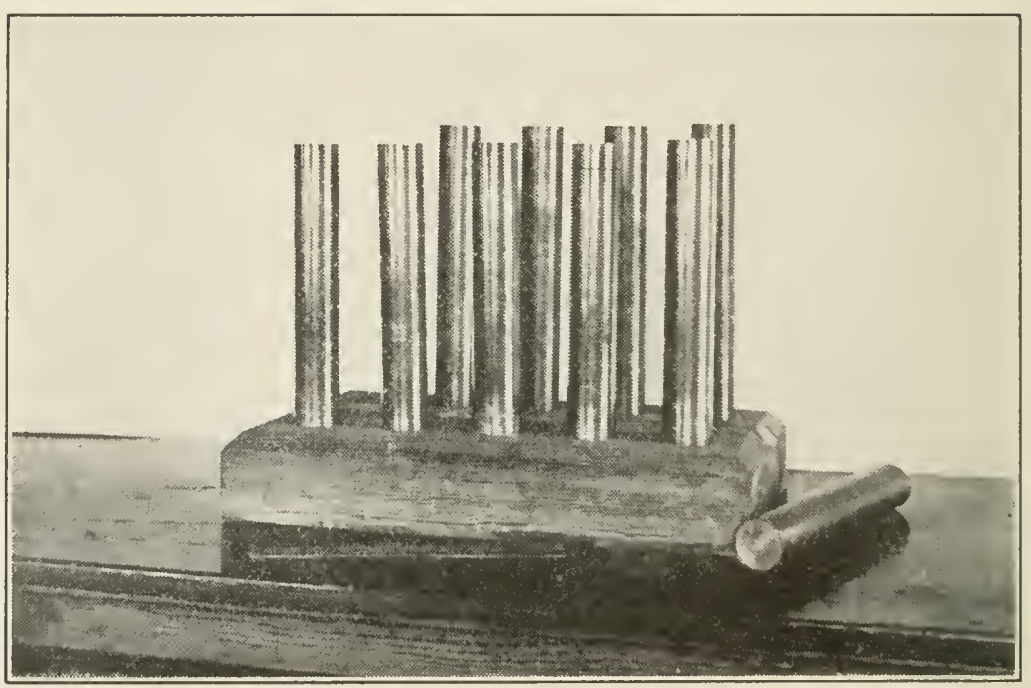

APPARATUS FOR THE DETERMINATION OF VOLUME IVEIGIT AND PORE SPACE

\section{METIIOD OF DETERMINATION}

Secure a brass cylinder ( $\mathrm{T}$ ), weigh empty, and fill with soil No. I, compacting it on the iron compactor by dropping the weight four times from the 6-inch mark after each measure of soil. Weigh the tube when level full and empty the soil back into the bin. Secure the weight of the cylinder full of each of the soils in this 
TIIE PIIYSICAL PROIERTIES OF SOHLS

STUDENT'S NOTES AND REPORT 


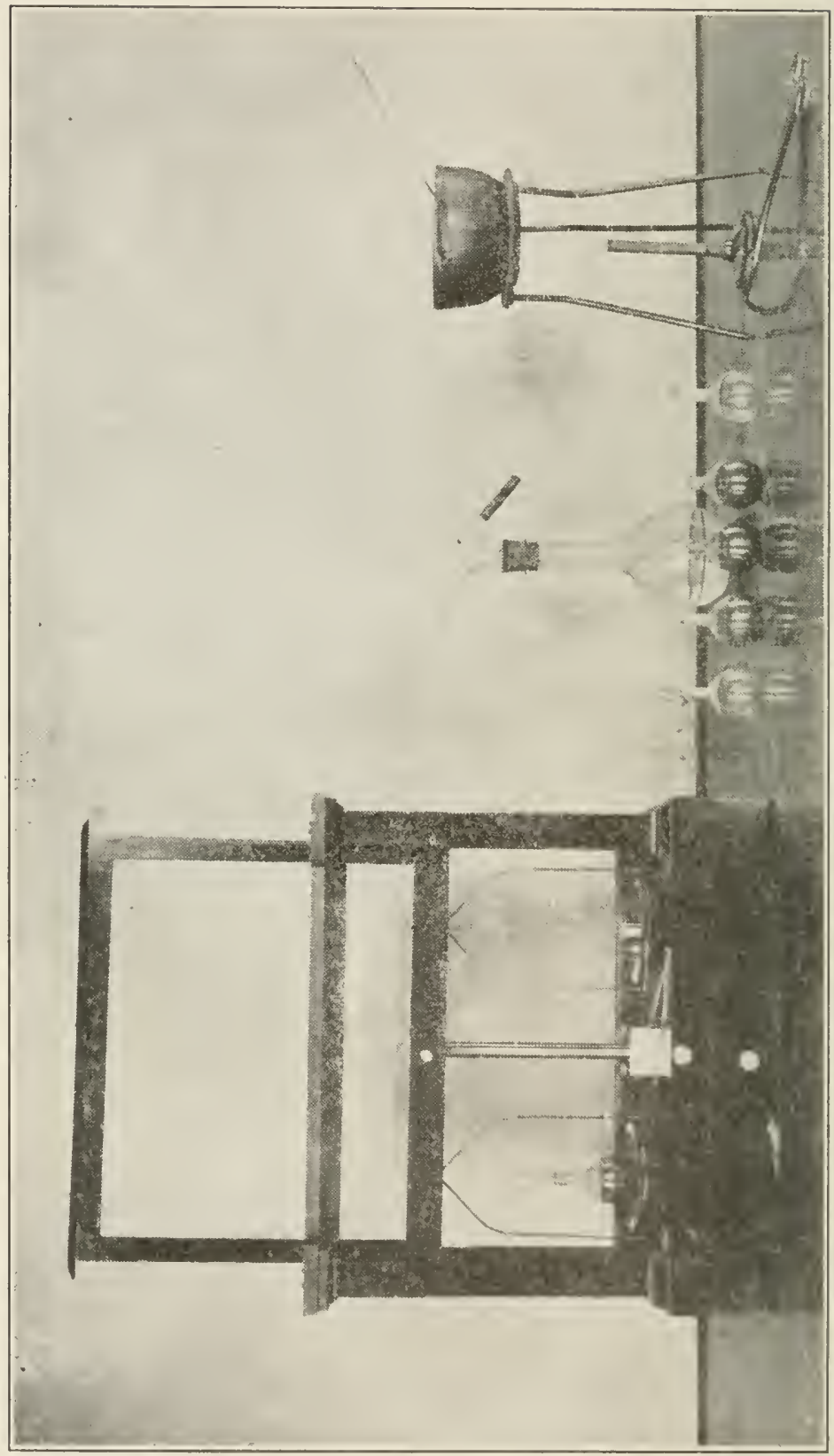

ช.

它

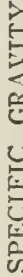

点

5

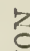

\&

5

点

(6)

동

E

6

恕

是

点 
STUDENT'S NOTES AND REPORT 
manner. With a graduated glass cylinder measure the amount of water required to fill the brass cylinder level full.

\section{CALCULATION}

Record all of the above weights in tabular form and calculate the apparent specific gravity and the weight in pounds per acre foot. Using the real specific gravity found in the preceding exercise, calculate the per cent of pore space in each soil by the formula given by King, "Physics of Agriculture," pp. I I4-I I6.

Discuss light and heavy soils, and the effect of texture upon the pore space.

REFERENCES :

King, "Physics of Agriculture," pp. I I4-I I6.

Snyder, "Soils and Fertilizers," pp. I2, I3.

\section{DETERMINATION OF PORE SPACE IN FIELD SOILS}

In order to determine the pore space in soils in place in the field it is necessary to know the real specific gravity and the weight of a given volume of the dry soil.

\section{METHOD OF DETERMINATION}

With sampling tube $(\mathrm{T})$ provided with a steel cutting edge, collect samples from the field which will represent the first and second foot of soil under different conditions, such as sod, cultivated field and stubble land. The surface of the ground is leveled and the sampling tube driven into the soil until the 12 -inch mark is exactly level with the ground surface. The entire sampler is then dug out, a broad spatula or a 
THE PHYSICAL PROPERTIES OF SOILS

STUDENT'S NOTES AND REPORT 


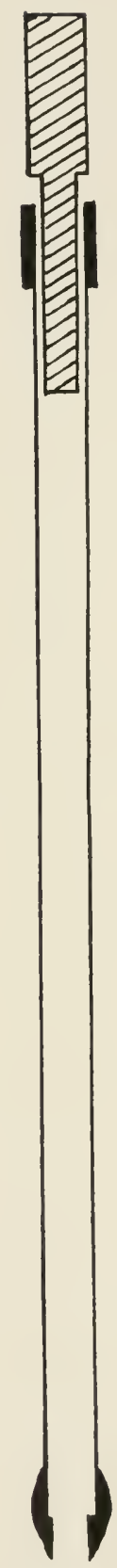

KING SOIL - SAMPLING TUBE WITH HA I MER. piece of steel being inserted under the lower end before the tube is removed. The tube is laid over on its side and the soil cut off flush with the cutting edge.

This operation is repeated to obtain a sample of the second foot.

The soil is removed from the sampler, taken to the laboratory, dried and weighed. The volume of the sample is calculated from the area of the end of the tube and the length of the core.

The cutting edge of the sampler is slightly smaller than the inside diameter of the tube in order to reduce the friction to a minimum and thus prevent the soil on the inside being forced down below the level of the surrounding ground.

\section{CALCULATION}

The real specific gravity of each sample is determined and the pore space calculated by the formula given by King, "Physics of Agriculture," pp. II4-iा 6.

Tabulate the results and discuss the factors which affect the volume weight and pore space of soils in the field.

References:

Burkett, "Soils," p. 37.

Wiley, "Agricultural Analysis," Vol. I., pp. I 43-I 45. 
THE PHYSICAL PROPERTIES OF SOILS

STUDENT'S NOTES AND REPORT 


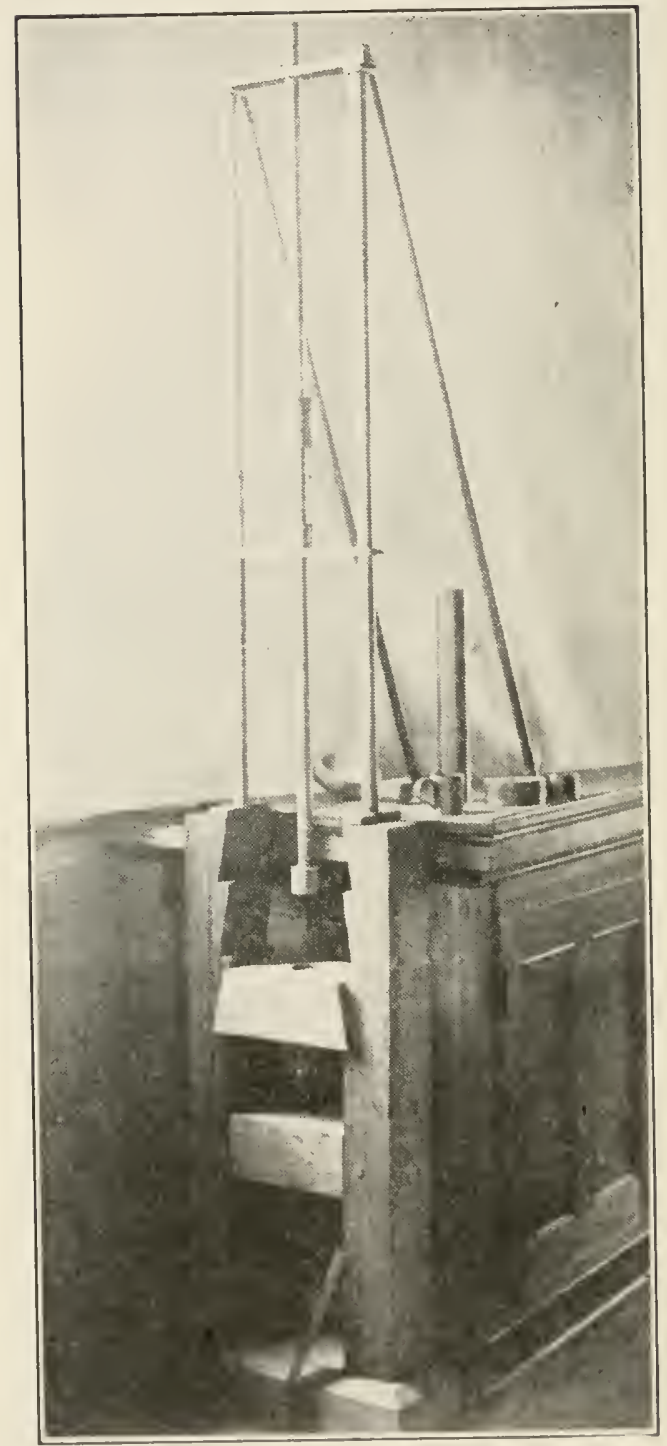

IRON COMPACTOR 
THE PHYSICAL PROPERTIES OF SOILS

STUDENT'S NOTES AND REPORT 


\section{FOURTH EXERCISE}

\section{PERCOLATION OF WATER THROUGH SOILS}

THE rate of percolation of water through soils is

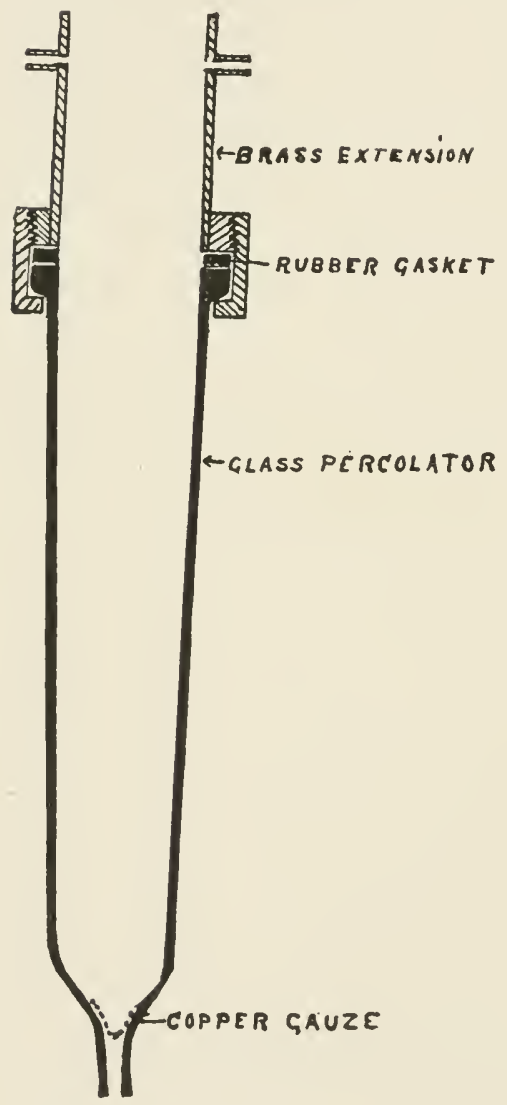

PERCOI.ATOR TUBF:

Sectional View largely dependent upon the texture of the soil and the amount of organic matter present.

Prepare four glass percolators by placing a piece of fine copper gauze in the bottom of each and filling to within one-half inch of the top, as follows:

Percolator No. I Sand.

Percolator No. 2 Mixture, three parts sand, one part organic matter.

Percolator No. 3 -

Mixture, one part

sand, one part organic matter.

Percolator No. 4Sandy loam.

Compact each percolator on the spring-board compactor by dropping the weight four times from the Io-inch mark. Fill the remaining half inch with sand to prevent puddling, clamp on the extensions ( $\mathrm{T}$ ) and 
admit the water. Use a siphon flask to keep the water at a constant level.

Note the time required for the water to reach the bottom in each; and the rate of percolation per hour under a given head of water, kept constant by means of the siphon flask.

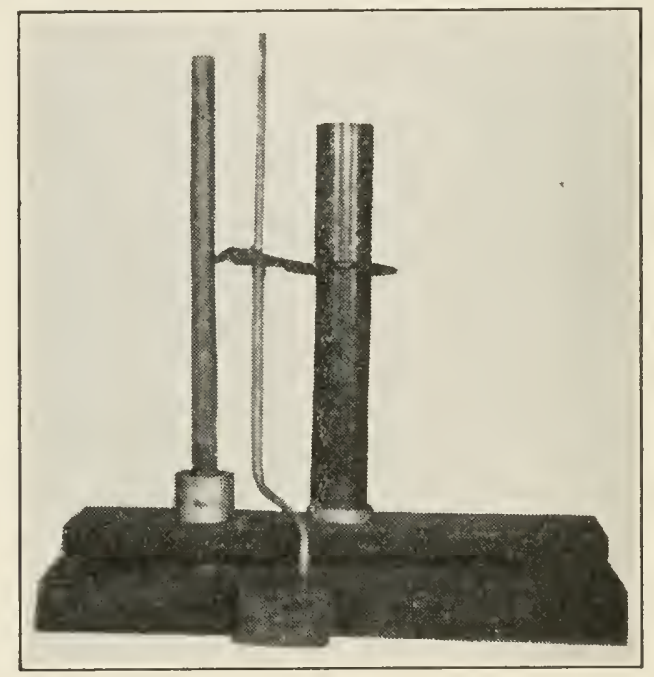

SPRING-BOARD CONIPACTOK

Repeat the above, using the following soils and mixtures:

Percolator No. I-Loam or silt.

Percolator No. 2-Mixture, one part loam one part organic matter.

Percolator No. 3-Clay.

Percolator No. 4-Mixture, one part clay, one part sand.

Tabulate the results and calculate the rate of percolation in surface inches per hour. Discuss the effect of texture and the presence of organic matter upon the rate of percolation. 
TIE PIIYSICIL, PROPERTIES OF SOILS

STUDENT'S NOTES AND REPORT 
REFERENCES :

Burkett, "Soils," pp. 38-39.

Hall, "The Soil," p. 72.

King, "The Soil," p. ryo.

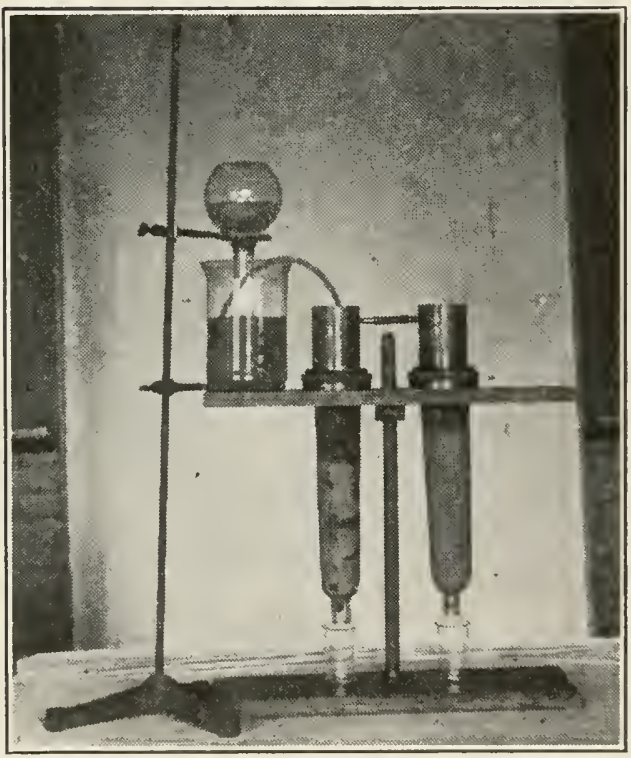

APPARATUS USED TO COMPARE THE RATE OF PERCOLATION IN DIFFERENT SOILS 
THE IIISICAL PROI'ERTIES OF SOILS

STUDENT'S NOTES AND REPORT 


\section{FIFTH EXERCISE}

\section{WATER-HOLDING CAPACITY OF SOILS}

Prepare six perforated bottom brass cylinders $(T)$ by placing a moist disk of muslin in the bottom of each. After weighing fill the cylinders to the mark as follows :

Tube No. 1-Sand.

Tube No. 2-Mixture, one part sand, one part organic matter.

Tube No. 3-Loam or silt.

Tube No. 4-Muck.

Tube No. 5-Clay.

Tube No. 6-Loam or silt, not compacted.

Compact each tube (except No. 6) on the iron compactor by allowing the weight to fall four times from the 6-inch mark after each measure of soil. Weigh and place in a tank in which the water is kept on a level

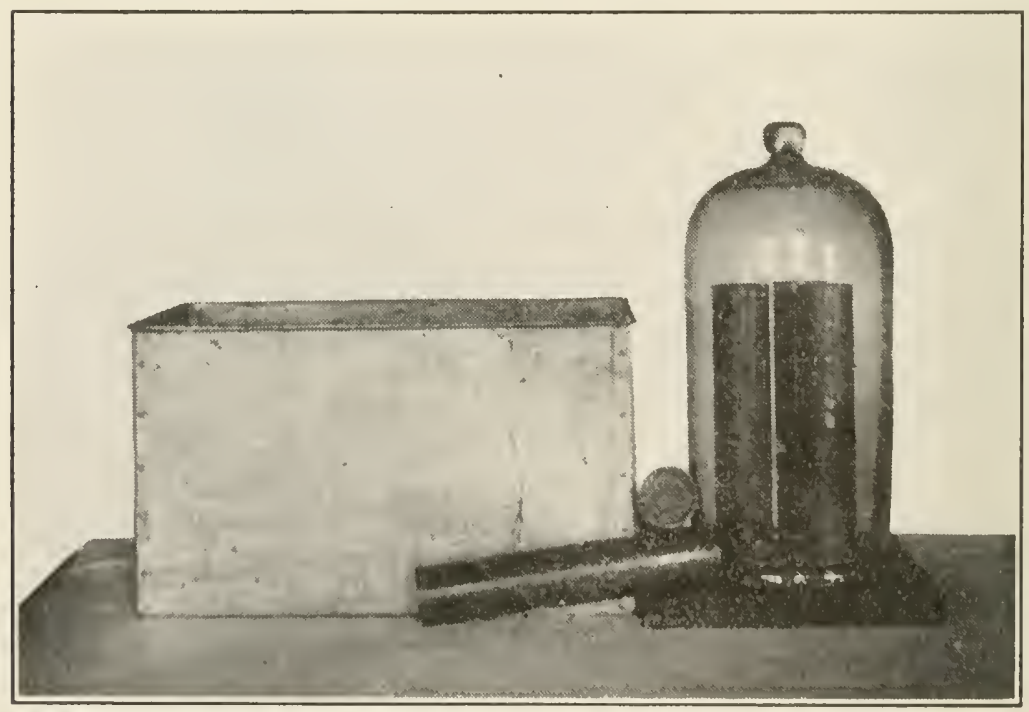

APPARATUS USED TO DETERMINE THE WATER-HOLDING CAPACITY OF SOILS 
THE PIISICAL PROPERTIES OF SUILS

39

STUDENT'S NOTES AND REPORT 
with the soil in the cylinders and allow to stand until free moisture appears on the surface. Remove from the tank, wipe dry, and weigh inmediately. Then place the cylinders on a draining board, under a bell jar ( $T$ ) and weigh every fortyeight hours for a week.

Tabulate the weighings and calculate the per cent of water required to saturate each soil and the per cent of capillary water retained in each after seven days of drainage. Discuss the factors effecting the water-holding power of soils.

REFERENCE :

Burkett, "Soils," pp. 40-42.

\section{THE DISTRIBUTION OF CAP- ILLARY WATER IN SOIL COL- UMNS.}

Prepare two 36-inch brass cylinders (T) in the manner described above, using sand in one and loam or silt in the other. At the end of the drainage period make moisture determinations at intervals throughout the length of the columuns by means of samples taken through the side tubes provided for that purpose.

How is the moisture distributed? Explain the cause of the unequal distribution.

REFERENCES :

Hall, "The Soil," p. 64.

King, "Physics of Agriculture," p. I I 4 .

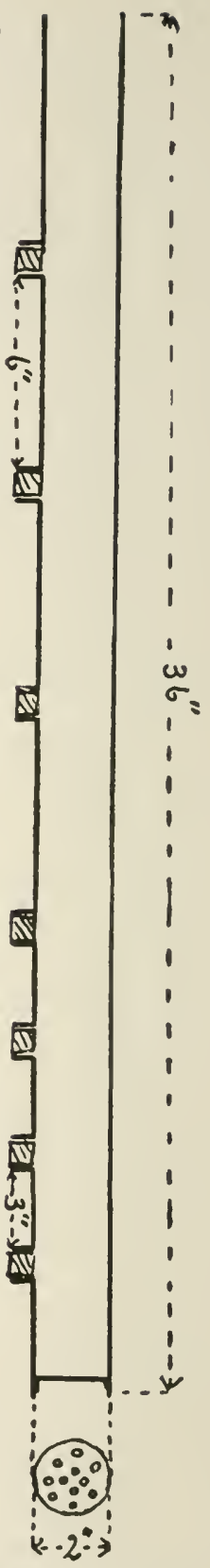

BRASS CILINDER

Provided with side tubes for studying the distribution of moisture in vertical columns of soil. It is also used in studying the lateral movement of capillary moisture. 
THE PIIYSICAL PROPERTIES OF SOILS

$4 \mathrm{I}$

STUDENT'S NOTES AND REPORT 
SIXTH EXERCISE

\section{FLOW OF AIR THROUGH LABORATORY STOCK SOILS}

Fill six aspirator tubes (T) with soils from the bins as follows:

Tube No. I-Sand.

Tube No. 2-Mixture, three parts sand, one part organic matter.

Tube No. 3-Loam or silt.

Tube No. 4-Muck.

Tube No. 5-Clay.

Tube No. 6-Mixture, three parts clay, one part organic matter.

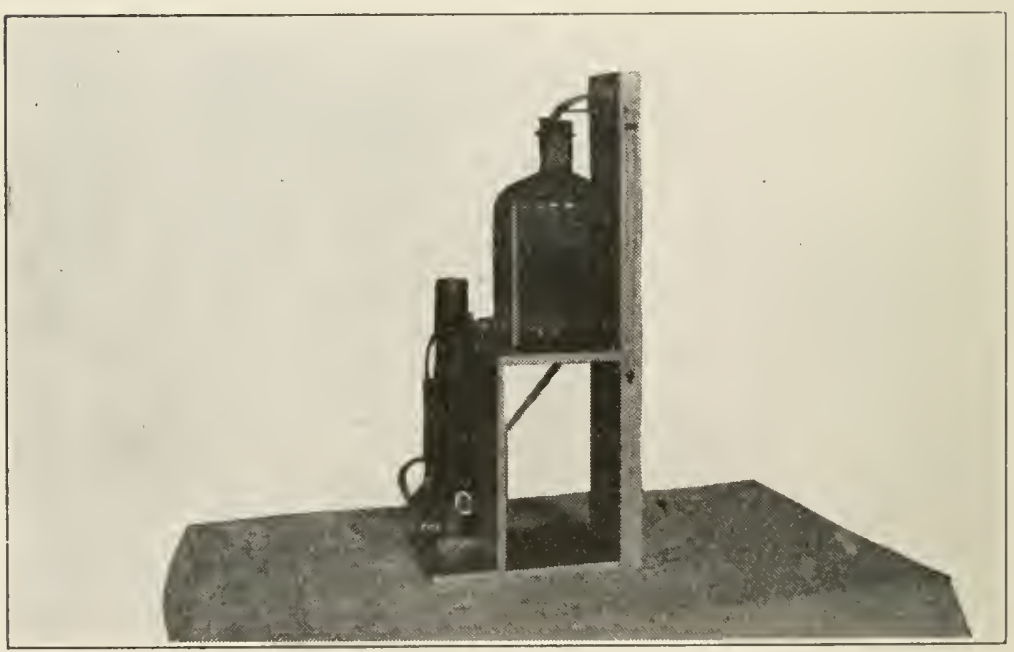

BOTTLE ASPIRATOR

Used in comparing the rate of flow of air through different soils

Compact each tube on the iron compactor by dropping the weight four times from the 6-inch mark after each measure of soil. Connect tube No. I to the as- 
THE PIIYSICAL PROPERTIES OF SOILS

STUDENT'S NOTES AND REPORT 
pirator bottle, open the stop-cock, and note the time necessary for one liter of water to escape. Repeat with each of the soils, and tabulate the results in liters per hour. Nake at least two determinations on each soil.

What effect has the texture of the soil and the presence of organic matter upon the rate of aeration?

\section{FLOW OF AIR THROUGH FIELD SOILS IN PLACE}

The permeability of undisturbed field soils may be determined with this apparatus in the manner described by King, "Physics of Agriculture," p. I27.

The movement of air in field soils in place may be determined also by the Heinrich method, as described by Wiley, "Agricultural Analysis," Vol. I., pp. I $\sigma_{3}, \mathrm{I} \sigma_{4}$.

References:

Burkett, "Soils," pp. 95-96.

King, "The Soil," p. 239.

Hilgard, "Soils," p. 279. 
STUDENT'S NOTES AND REPORT 


\section{SEVENTH EXERCISE}

\section{CAPILLARY RISE OF MOISTURE IN SOILS}

Prepare five brass capillary tubes ( $T$ ) and fill them as follows:

Tube No. I-Sand.

Tube No. 2-Mixture, three parts sand, one part organic matter.

Tube No. 3-Loam or silt.

Tube No. 4-Clay.

Tube No. 5-Mixture, three parts clay, one part organic matter.

Compact each tube on the spring-board compactor by dropping the weight four times from the ro-inch mark, and weigh. Place the tubes in a rack with the lower ends dipping into a tray of water, the depth of the water being kept at a constant level by means of a siphon flask. Record the height of the rise of water after thirty minutes, one hour, and every twenty-four hours thereafter for seven days.

Express the results in tabular form and by means of curves. Discuss the effect of texture and the presence of organic matter upon the capillary rise of moisture.

REFERENCES :

Hall, "The Soil," pp. 68 and 94.

Hilgard, "Soils," pp. 202-208.

\section{INTERRUPTION OF THE CAPILLARY RISE OF MOISTURE}

Fill three brass tubes ( $T$ ) to the depth of one foot with sandy loam soil, and place them in a rack with 


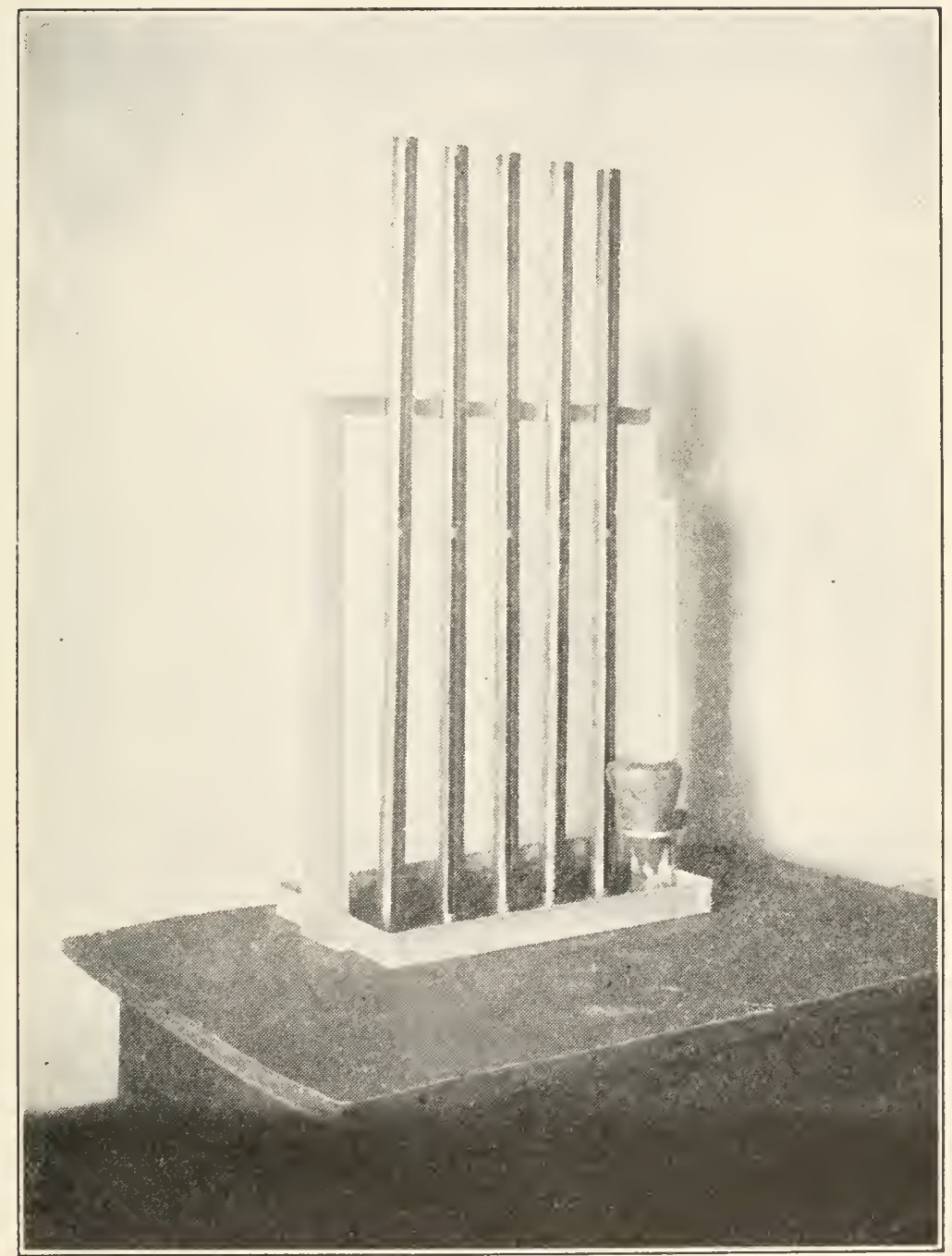

APPARATUS USED TO COMPARE THE CAPILLARY RISE OF MOISTURE IN DIFFERENT SOILS

The brass tubes are lined with thin celluloid and have a slit the length of one side. The inverted flask keeps the water in the tray at a constant level. 
the lower ends dipping into a tray containing one inch of water. After the water has risen to the top of the soil, add to the first about one inch of moist cut straw, and to the second the same quantity of well-rotted organic matter, and to the third nothing. Then add to each tube about six inches of dry soil to represent the furrow slice.

Observe the effect of the organic matter upon the capillary rise of moisture, and draw conclusions as to the effect of plowing under heavy top-dressings of manure just before seeding.

Reference:

Vivian, "First Principles of Soil Fertility," pp. I02 and I68. 
THE PHYSICAL PROPERTIES OF SOILS

STUDENT'S NOTES AND REPORT

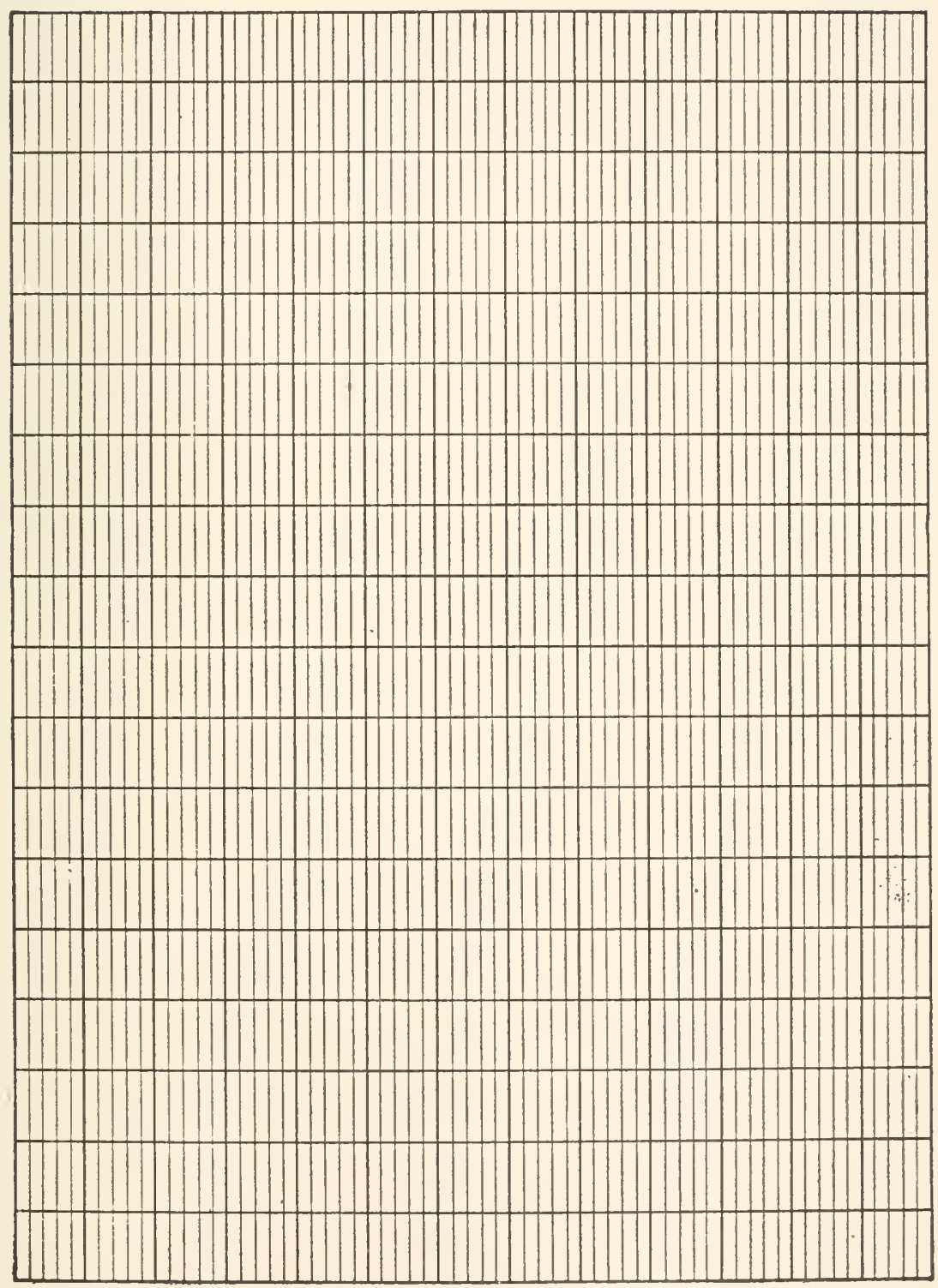

PLAIN CO-ORDINATE PAPER 


\section{EIGHTH EXERCISE}

\section{CONTINUOUS RISE OF CAPILLARY MOISTURE}

AT the beginning of the term the instructor will fill twelve long capillary tubes with the following materials :

Tube No. I-Clay.

Tube No. 2-Loam or silt.

Tube No. 3-Sandy loam.

Tube No. 4-Sand.

Tube No. 5-Muck.

Tube No. 6-Sand, 100 to 120 mesh.

Tube No. 7-Sand, 6o to 80 mesh.

Tube No. 8-Sand, 20 to 40 mesh.

Tube No. 9-Mixture, one part clay, one part muck.

Tube No. 10-Mixture, one part sand, one part muck.

Tube No. I I-Mixture, one part clay, one part sand.

Tube No. 12-Mixture, one part loam, one part sand.

After filling, these tubes are placed in a rack with their lower ends resting in a tray into which water is admitted to the depth of one inch. The experiment is now ready for observation, and each student in the class is required to make measurements and to record the height of the rise of moisture at stated intervals during the term. Observations should be made every hour during the first day and at daily intervals for the 
TIIE PHYSICAL PROPERTIES OF SOILS

STUDENT'S NOTES AND REPORT 
first week. After the first week the intervals may be lengthened to three days.

A short time before the end of the term make a close comparison of the different tubes. Plot a curve showing the height of the water at each observation. Discuss the effect of texture and the presence of organic matter upon the capillary rise of moisture as shown by the behavior of the soils in these tubes.

How do these results compare with those obtained in the preceding exercises?

ReFerences :

Hilgard, "Soils," pp. 202-207.

King, "Physics of Agriculture," pp. I6I-I65.

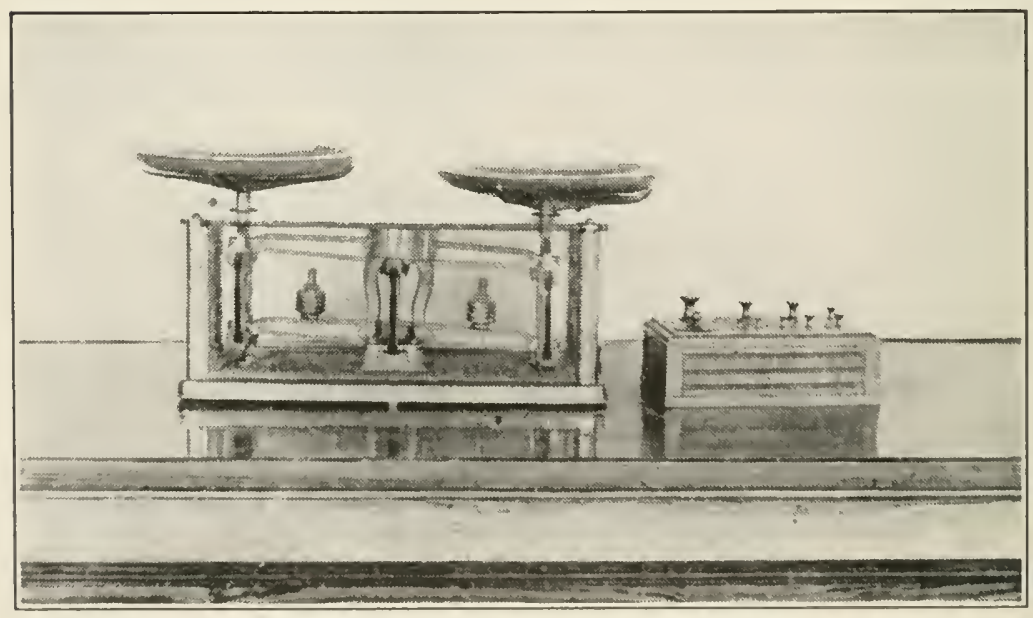

TORSION HALANCE

Used for all rough weighings. A chemical balance is used where greater accuracy is required 
STUDENT'S NOTES AND REPORT 


\section{NINTH EXERCISE}

\section{THE LATERAL MOVEMENT OF CAP- ILLARY MOISTURE}

THE forces which produce capillary movement of moisture in soils in the field may act in direct opposition to, or at any angle with the force of gravity. During periods of drought, growing plants may be supplied with water by a vertical movement from the moist sub-soil or by a lateral movement from the adjacent surface soil.

Prepare the two brass cylinclers used in the Fifth Exercise, Part II., by filling one with loam or silt and the other with clay. Make the soils up to I5 or 20 per cent of moisture and pack the cylinders level full by means of a wooden rammer. Cap the lower end, and tie a piece of moist cheese-cloth over the top of each cylinder and place them in a horizontal position. Weigh at the beginning of the experiment and at twenty-four hour intervals for one week.

At the end of the period take samples through the side tubes and determine the per cent of moisture in each.

Discuss the results with respect to the total loss of moisture and to its distribution, at the close of the experiment.

\section{References :}

Bureau of Soils, Bulletin No. Io.

Bureau of Soils, Bulletin No. 38 . 
THE PHYSICAL PROPERTIES OF SOILS

55

STUDENT'S NOTES AND REPORT

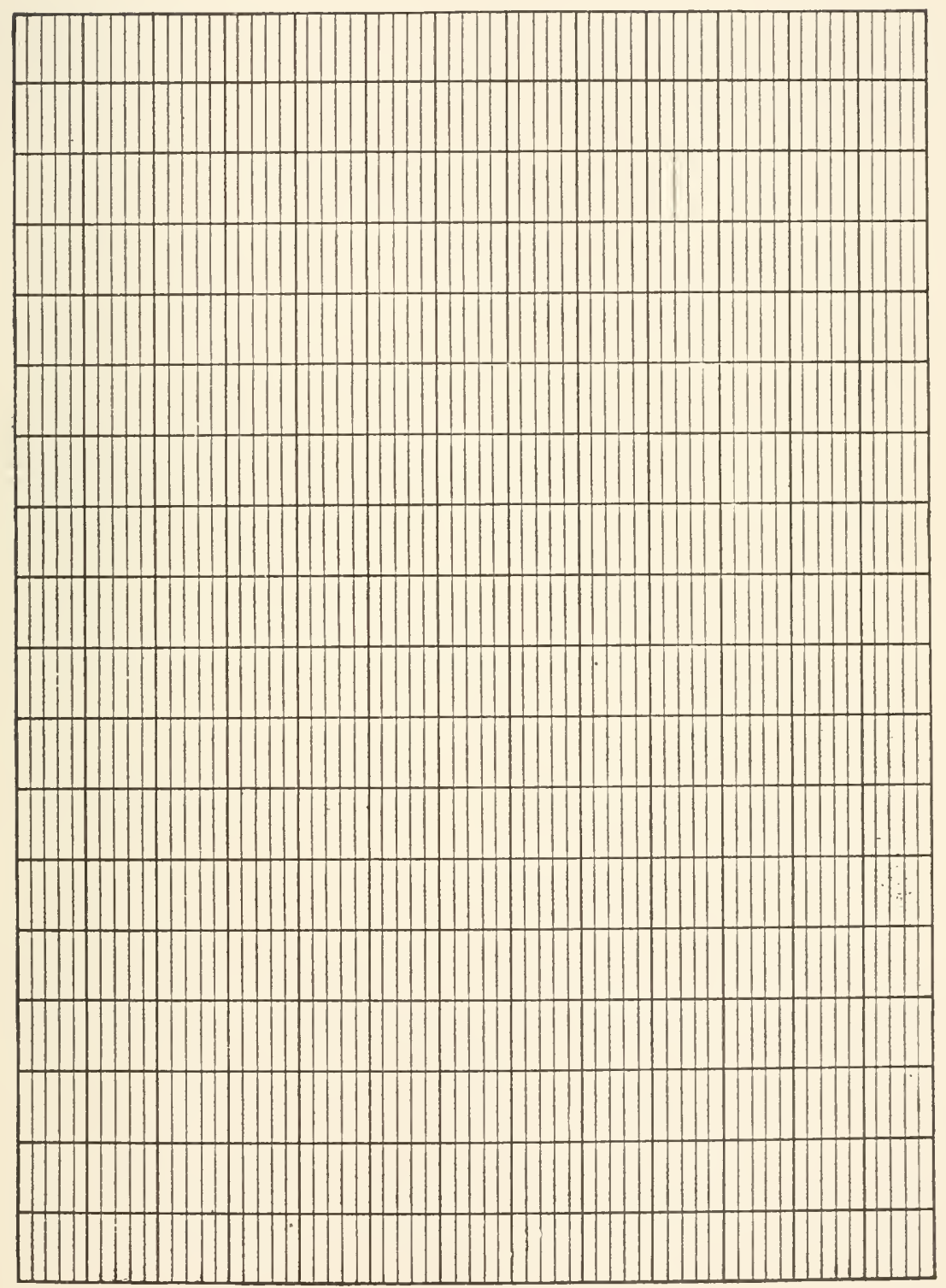

PLAIN CO-ORDINATE PAPER 


\section{TENTH EXERCISE}

\section{CO-EFFICIENT OF EVAPORATION}

Prepare four evaporimeters (T) and fill level full with the following soils:

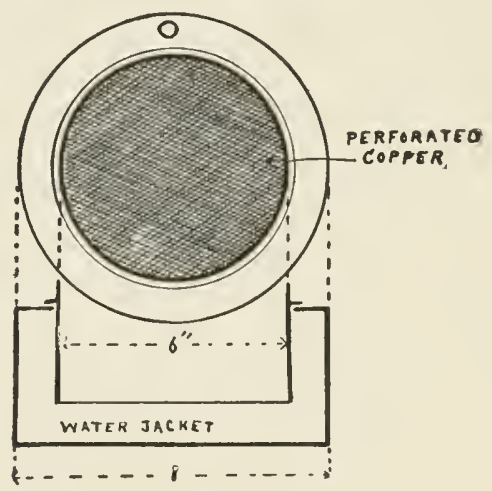

\section{EVAPORIMETER}

Sectional View

Evaporimeter No. I-Sand.

Evaporimeter No. 2-Loam or silt.

Evaporimeter No. 3-Muck.

Evaporimeter No. 4-Clay.

Fill the water-jackets, and after the water has appeared at the surface weigh the entire system. A crystallizing dish having the same amount of exposed surface should be filled with water and weighed at the same time. Expose the surfaces to the air for twentyfour hours, weigh and calculate the rate of evaporation in pounds per acre.

Empty the water from the jackets and determine the loss from each surface hy evaporation by forty-eighthour periods for one week. 
STUDENT'S NOTES AND REPORT 


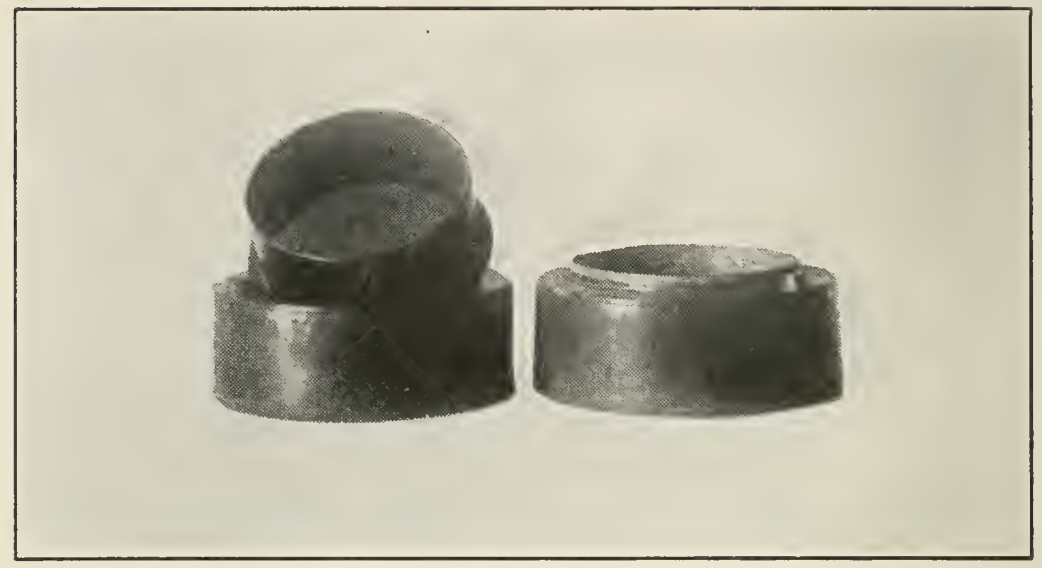

EVAPORIMETERS

Apparatus used for comparing the loss of moisture from different soils by evaporation

Tabulate the results and compare the rate of evaporation from the different soils with each other and with that from the water-free surface.

Discuss the effect of texture upon the rate of evaporation, and plot curves to represent the rate of evaporation from each soil.

REFERENCES :

Burkett, "Soils," p. I66.

Fletcher, "Soils," pp. 88, 89.

Wiley, "Agricultural Analysis," Vol. I., pp. I6o, I6I. 
THE PIISICAL PROPERTIES OF SOILS

STUDENT'S NOTES AND REPORT

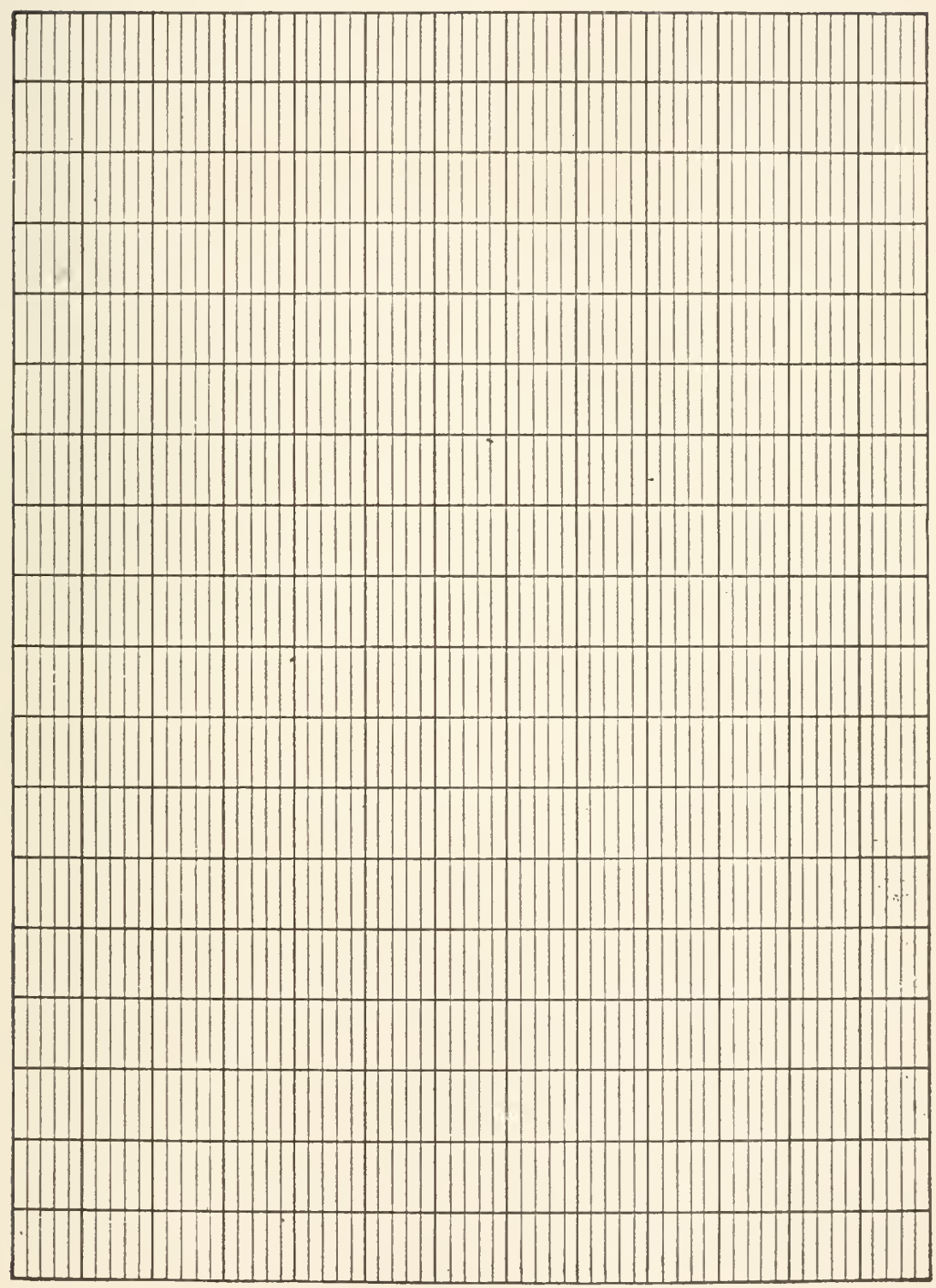

PLAIN CO-ORDINATE PAPER 


\section{ELEVENTH EXERCISE}

\section{EFFECT OF MULCHES UPON THE RATE OF EVAPORATION}

Mulching the soil either by earth mulches (tillage)

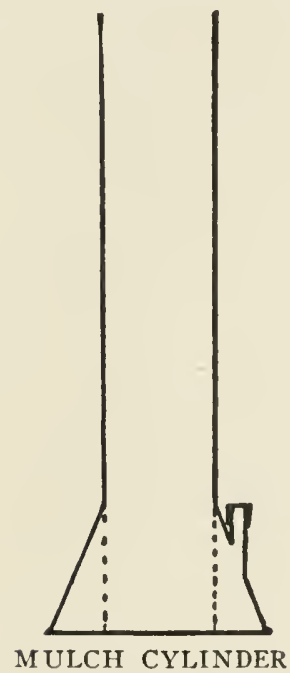

Sectional View

or by artificial mulches (straw or manure) is the most effective means of conserving soil moisture.

Fill five galvanized iron cylinders ( $\mathrm{T}$ ) to within one-half inch of the top with the same soil, compacting uniformly. Fill the water-jackets and apply pressure until the moisture appears on the surface of each soil. Remove the water from the jackets and treat the surfaces of the cylinders as follows:

No. I-No treatment.

No. 2-Cultivate one inch deep each day.

No. 3-Compact the surface.

No. 4-Remove the surface inch of soil and replace with sand.

No. 5-Remove the surface inch of soil and replace with cut straw.

Care must be taken to have the finished surface of the soil in all of the cylinders at exactly the same distance below the rim, and to expose all of the cylinders to the same atmospheric conditions. 
THE PHYSICAL PROPERTIES OF SOILS

STUDENT'S NOTES AND REPORT 


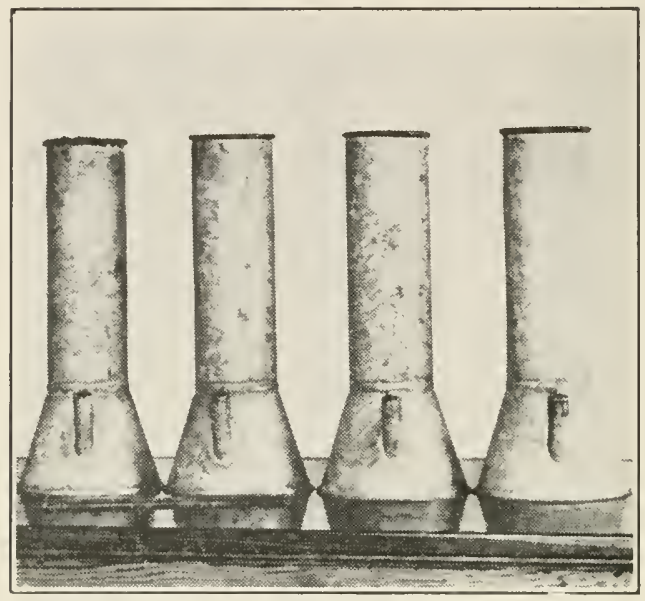

\section{GALVANIZED IRON CYLINDERS}

Used in studying the effectiveness of different mulches in conserving soil moisture

Weigh and record the loss in weight at forty-eighthour intervals for one week. Calculate the loss in tons per acre for each treatment, and discuss the relative effectiveness of the different mulches.

REFERENCES:

Burkett, "Soils," Chapter XXI.

King, "The Soil," p. I94.

Hall, "The Soil," p. 97. 
THE PHYSICAL PROPERTIES OF SOILS

STUDENT'S NOTES AND REPORT 


\section{TWELFTH EXERCISE}

\section{THE ABSORPTIVE POWER OF SOILS}

IN common with other finely divided substances, soils have the power of absorbing water vapor and other gases from the atmosphere. The hygroscopic capacity of different soils may be compared by exposing them to a saturated atmosphere for a given length of time under standard temperature conditions, and observing the increase in weight.

\section{METHOD OF DETERMINATION}

Weigh out carefully into shallow aluminum trays or pans, 25-gram samples of each of the following soils :

Tray No. I-Sand.

Tray No. 2-Loam or silt.

Tray No. 3-Clay.

Tray No. 4-Mixture, one part sand, one part organic matter.

Tray No. 5-Mixture, one part loam, one part organic matter.

Spread thin in the trays, dry to constant weight, either in a drying oven or over sulphuric acid, cool in a desiccator, and place the trays, with lids off, into a constant temperature chamber in which the air is kept saturated with water vapor. Allow the samples to remain in contact with the saturated atmosphere until a constant weight is obtained. An empty tray should be kept with those containing the soil, and its 
THE PHYSICAL PROPERTIES OF SOILS

STUDENT'S NOTES AND REPORT 
increase in weight deducted from the total increase in the soil trays.

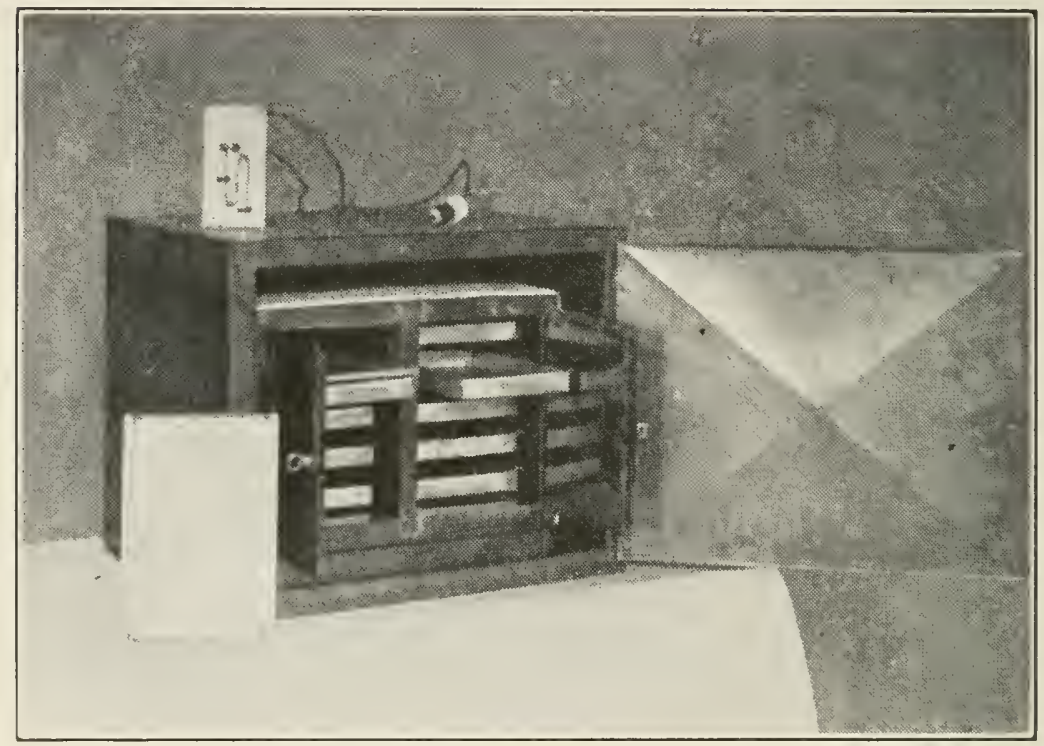

CONSTANT TEMPERATURE CHAMIBER

Used in determining the hygroscopic capacity of soil. Heat is supplied by means of a coil of fine wire attacled to the lighting circuit and coiled around the inner chamber. An air thermometer regulates the temperature automatically.

Tabulate the results and express the absorptive capacity of each soil in per cent and as pounds per acre-foot.

How is the absorptive capacity effected by the texture of the soil and by the presence of organic matter?

References:

Hall, "The Soil," p. 8I.

King, "The Soil," p. 252. 
TIE PHYSICAL PROPERTIES OF SOILS

STUDENT'S NOTES AND REPORT 


\section{THIRTEENTH EXERCISE}

\section{THE FLOCCULATING EFFECT OF LIME UPON CLAY SOILS}

TuE addition of lime to a clay soil produces flocculation, or a grouping together of the fine soil grains into granules, which act physically very much as single soil grains. The effect is equivalent to increasing the size of the soil grains and giving to the soil the properties of a much coarser textured material. Fine grained, stiff, clay soils tend to become loose and friable when flocculation is induced.

Flocculation is best shown in a soil suspended in water. Work up in a mortar two Io-gram samples of clay soil and place one in each of two glass cylinders. Fill two-thirds full of distilled water. Leave one cylinder untreated, and to the other add $20 \mathrm{cc}$. of a saturated solution of lime-water. Shake both for several minutes and note the formation of floccules in the tube containing lime. Examine some of the suspended material from both cylinders under the microscope.

How does lime aid in clearing the solution? What other materials are effective in producing flocculation?

Set the cylinders aside and note the time required for each to become clear by settling. Discuss the effect of lime upon the physical character of the soil in the field.

ReFERENCES :

Burkett, "Soils," Chapter XI.

King, "The Soil," p. 30.

Hall, "The Soil," pp. 38-40. 
THE PHYSICAL PROPERTIES OF SOILS

\section{STUDENT'S NOTES AND REPORT}




\section{FOURTEENTH EXERCISE}

\section{THE POWER OF SOILS TO RETAIN FER- TILIZERS APPLIED IN SOLUTION}

ALL soils have the power of removing from solution certain salts which may be dissolved in percolating waters. This is accomplished by direct absorption in some cases, while in others it involves a preliminary chemical change. The extent to which different fertilizer constituents are retained has a direct bearing upon the theory and practice of manuring.

Prepare two glass percolator tubes and place a piece of fine copper gauze in the bottom of each. Make up to about 15 per cent of moisture a sufficient quantity of sandy loam to fill both tubes. Carefully fill both percolators to the same depth, compacting the soil gently and uniformly by means of a wooden rammer.

Suspend both percolators, and pour into one a solution of n-1OO sodium phosphate and into the other a solution of n-IOO sodium nitrate, and keep adding the solution until it begins to percolate from the bottom.

Collect the filtrates separately and test each for the salts applied and compare with the original solutions.

A very rough quantitative test for phosphorus and nitrogen will serve a useful purpose, but if the apparatus is available exact quantitative determinations should be made on both the original solution and the filtrates.

What practical bearing has the experiment upon the time and manner of applying commercial fertilizers to soils in the field? 
THE PHYSICAL PROPERTIES OF SOILS

\section{STUDENT'S NOTES AND REPORT}


REFERENCES :

Hall, "The Soil," Chap. VIII.

Vivian, "First Principles of Soil Fertility," p.

I93.

Bureau of Soils, Bulletin No. 32 . 
TIIE PIIYSICIL PROPERTIES OF SOILS

73

STUDENT'S NOTES AND REPORT 


\section{FIFTEENTH EXERCISE}

\section{THE SPECIFIC HEAT OF SOILS}

THE specific heat of a body is the ratio between the amount of heat necessary to raise a given weight of the substance one degree, and the amount necessary to raise the temperature of the same weight of water one degree. The specific heat of dry soil is usually between 0.20 and 0.30 , but this is greatly modified by the presence of moisture, the wetter the soil the larger the quantity of heat required to raise the temperature a given number of degrees.

APPARATUS FOR TIIE DETERMINATION OF THE SPECIFIC HEAT OF SOILS

The apparatus consists of a double-walled cylindrical heater $(A)$ made of heavy copper, and connected to a steam-system. Extending through the heater is a hollow core $(C)$, open at both ends, but provided with movable covering at either end. The calorimeter consists of a polished brass cup (E) of about 5oocc. capacity, supported on corks and insulated from outside influences by means of an air space $(F)$ and an outer jacket $(G)$ of wood and felt. The lid to the outer jacket is also covered with heavy felt and carries a thermometer graduated to tenths of degrees.

The calorimeter is mounted on a slicling base, which permits it to be brought under the heater at the proper moment to receive the heated sample.

\section{METHOD OF DETERMINATION}

Determine the specific heat of a sand and of a clay soil, first in the dry state and then in a moist 


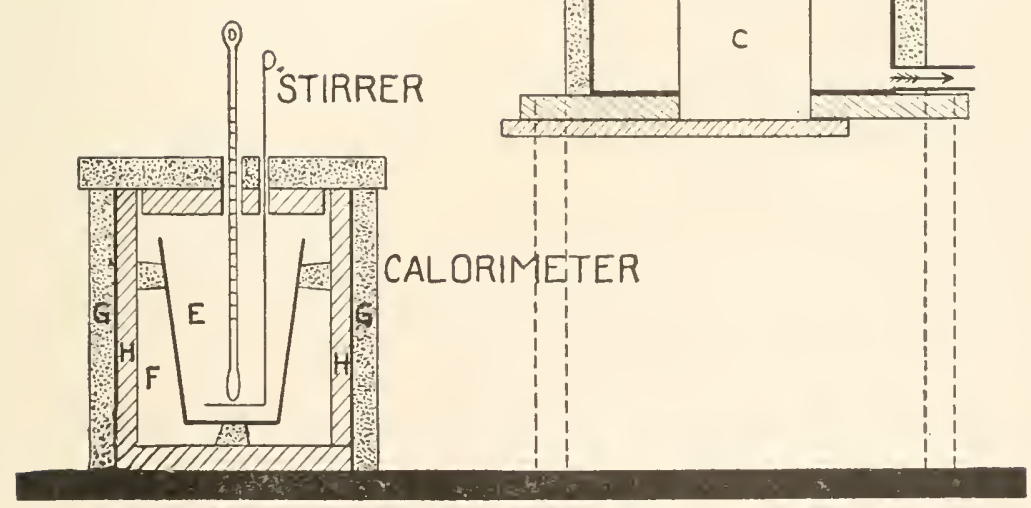

SECTIONAL VIFW OF THE APPARATLS USED IN THE DETERMINATION OF THE SPECIFIC HEAT OF SOILS 
condition. If time will permit study also the effect of organic matter upon the specific heat.

The soils are heated in the oven to drive off the hygroscopic moisture, and two 25 -gram samples from each are weighed out, one to be used for the determination of the specific heat of dry soil and the other made up to 5 per cent of moisture for the determination on the moist sample.

The sample under consideration is enclosed in a bag of thin oiled paper and suspended, by a fine thread, in the heater near a delicate thermometer. The steam is turned into the jacket, and the soil is left in the heater until a uniform temperature is reached. This will require from one-half to one hour. Meanwhile the calorimeter $(E)$ is partly filled with water which has stood in the room for a long time and has acquired, as nearly as possible, the room temperature. The quantity of water should be such that the water value of the entire system shall amount to exactly Ioo or I 50 grams of pure water.

A few minutes before the soil is brought into the calorimeter the stirrer should be started, and the thermometer read at frequent intervals. If the thermometer shows a constant reading the calorimeter is quickly brought under the heater, the sample lowered into it, and the thread cut. The calorimeter is removed as promptly as possible, the lid replaced, and the soil thoroughly incorporated with the water by the stirring apparatus. The thermometer is again read at frequent intervals until the maximum is reached, as indicated by a gradual fall in temperature.

The specific heat is calculated by the following formula, in which the loss in heat by the soil is 
THE PHYSICAL PROPERTIES OF SOILS

STUDENT'S NOTES AND REPORT 
equated against the gain in heat by the water in the calorimeter.

$$
m C\left(t_{n}-T\right)=M\left(T-T_{0}\right)
$$

Specific heat $\mathrm{C}=\frac{M\left(T-T_{0}\right)}{m\left(t_{n}-T\right)}$

where $m=$ mass of soil taken.

$t_{0}=$ the temperature of the mass.

$M=$ mass of water including water

value of the calorimeter.

$T_{\text {" }}=$ the temperature of the mass.

calorimeter.

$T=$ final temperature of water in the calorimeter.

$C=$ specific heat.

\section{ReFERENCES :}

King, "Physics of Agriculture," p. 29 and pp. $215,216$.

Wiley, "Agricultural Analysis," Vol. I., pp. IOO-I IO. 
STUDENT'S NOTES AND REPORT 


\section{SIXTEENTH EXERCISE}

\section{MECHANICAL ANALYSIS OF SOILS- BOTTLE METHOD}

By this method an approximate analysis can be made without the use of a centrifugal machine. The

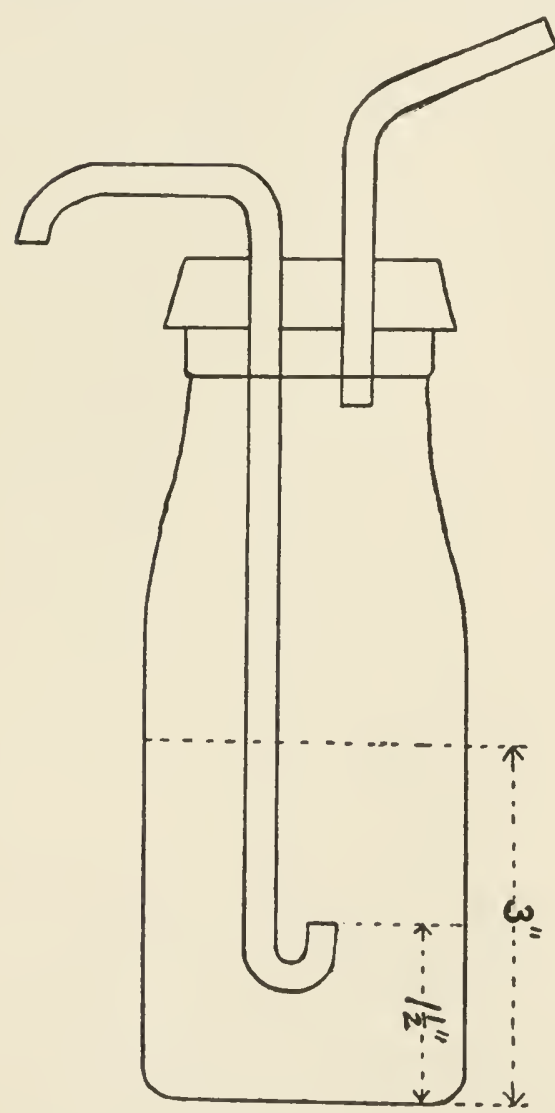
silt and clay groups are estimated together.

Duplicate a n a 1 y s e s should be made upon prepared stock samples, in order to give the student practice. As soon as he is familiar with the details of the separation, field samples should be used. For the method of preparing field samples see the instructions given on page 96 .

METHOD OF MAKING THE SEPARATIONS

Take twenty or thirty grams of dry, pulverized, sifted soil; mix thoroughly, and dry in the oven and cool in a APPARATUS USED IN THE BOTTLE METHOD OF M EC H A N I C A L ANALYSIS (after Mosier).

desiccator. Weigh out two 5-gram portions. Ignite one of these samples and calculate the loss on ignition. Transfer the other sample to an S-ounce 
THE PHYSICAL, PROPERTIES OF SOILS 8I STUDENT'S NOTES AND REPORT 
sterilizing bottle (T), add about I $_{5} \mathrm{O}$ cc. of distilled water and ten drops of ammonium hydrate to break up flocculation. Place the bottle in the mechanical shaker and agitate until, when viewed under the microscope, the soil particles are free from each other and present a clear-cut appearance.

Transfer from the shaker-bottle to the apparatus shown on page $80(\mathrm{~T})$. Adjust this bottle so that the opening into the long tube will be $\mathrm{I} / 2$ inches from the bottom. Fill to the 3 -inch mark by means of a small jet of sufficient force to thoroughly stir up the contents.

Allow the apparatus to stand until a microscopic examination shows that all of the sand grades have settled below the opening of the tube. Blow off into a beaker all of the liquid above the end of the tube, and continue the operation of filling, settling and blowing off until the grades that settle contain no silt or clay. The liquid blown off contains the silt and clay, the amount of which is determined by evaporating to dryness and weighing. No attempt is made at this time to separate the silt from the clay.

The decanting process may be continued for the separation of the finest sand grades, or the material may be dried and the separation made by means of a nest of sieves. After the removal of the sands the bottle is used to accomplish the separation of the clay from the silt.

Tabulate the results of the analyses.

REFERENCE:

Bulletin No. 24, Bureau of Soils. 
TIIE PIIISICIL PROPERTIES OF SOILS

STUDENT'S NOTES AND REPORT 


\section{SEVENTEENTH EXERCISE}

\section{MECHANICAL ANALYSIS OF SOILS-CEN- TRIFUGAL METHOD}

MAKE duplicate analyses of sandy loam and of clay soil from the bins. Then, if time will permit, make analyses of samples from the home farm.

The method by which the separation is accomplished is as follows:

Take twenty to thirty grams of dry, pulverized soil, mix thoroughly and dry in the oven. Cool in a desiccator, weigh out two 5-gram portions, transfer one to an 8-ounce sterilizing bottle and the other to a porcelain dish for ignition.

Add to the sample in the sterilizing bottle about I5occ. of distilled water and ten drops of ammonium hydrate to break up flocculation. (For the method of preparing field samples see page 96.) Place the bottle in a mechanical shaker and agitate until, when vicwed under the microscope, the soil particles are all free from each other and present a clear-cut appearance. Transfer the contents to the centrifugal testtube by means of a jet of distilled water.

The separates to be determined are as follows:

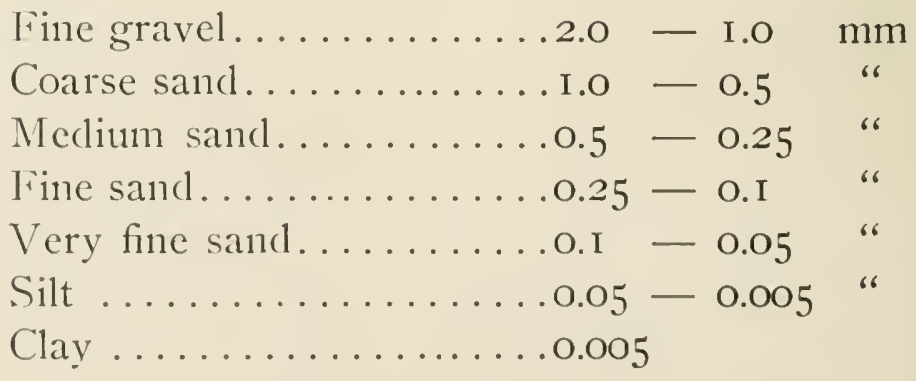


THE PHYSICAL PROPERTIES OF SOILS

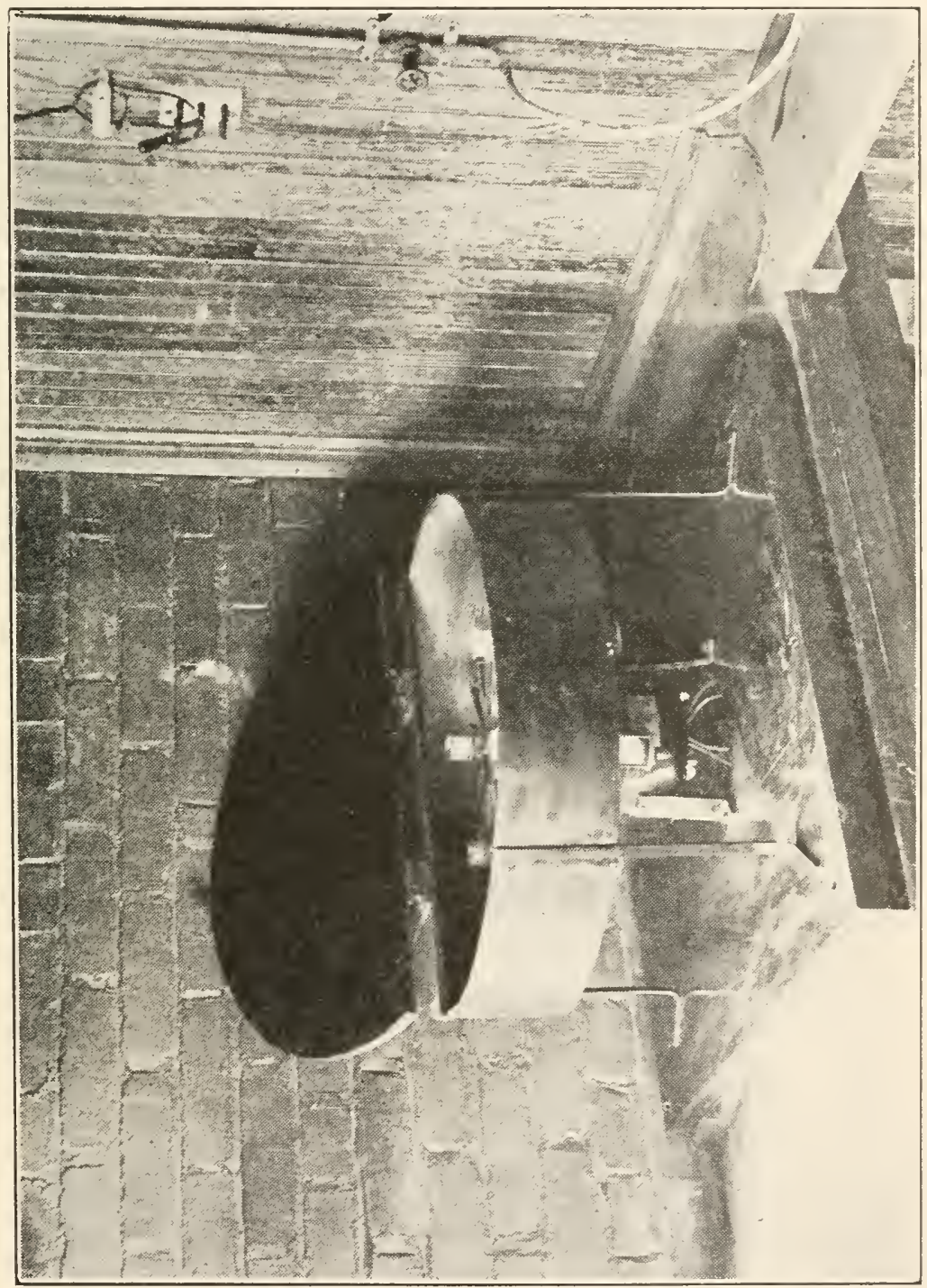

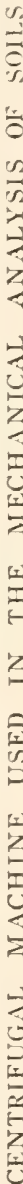




\section{CLAY SEPARATION}

Whirl the tubes in the centrifuge about one minute, or until all of the particles larger than clay ( 0.005

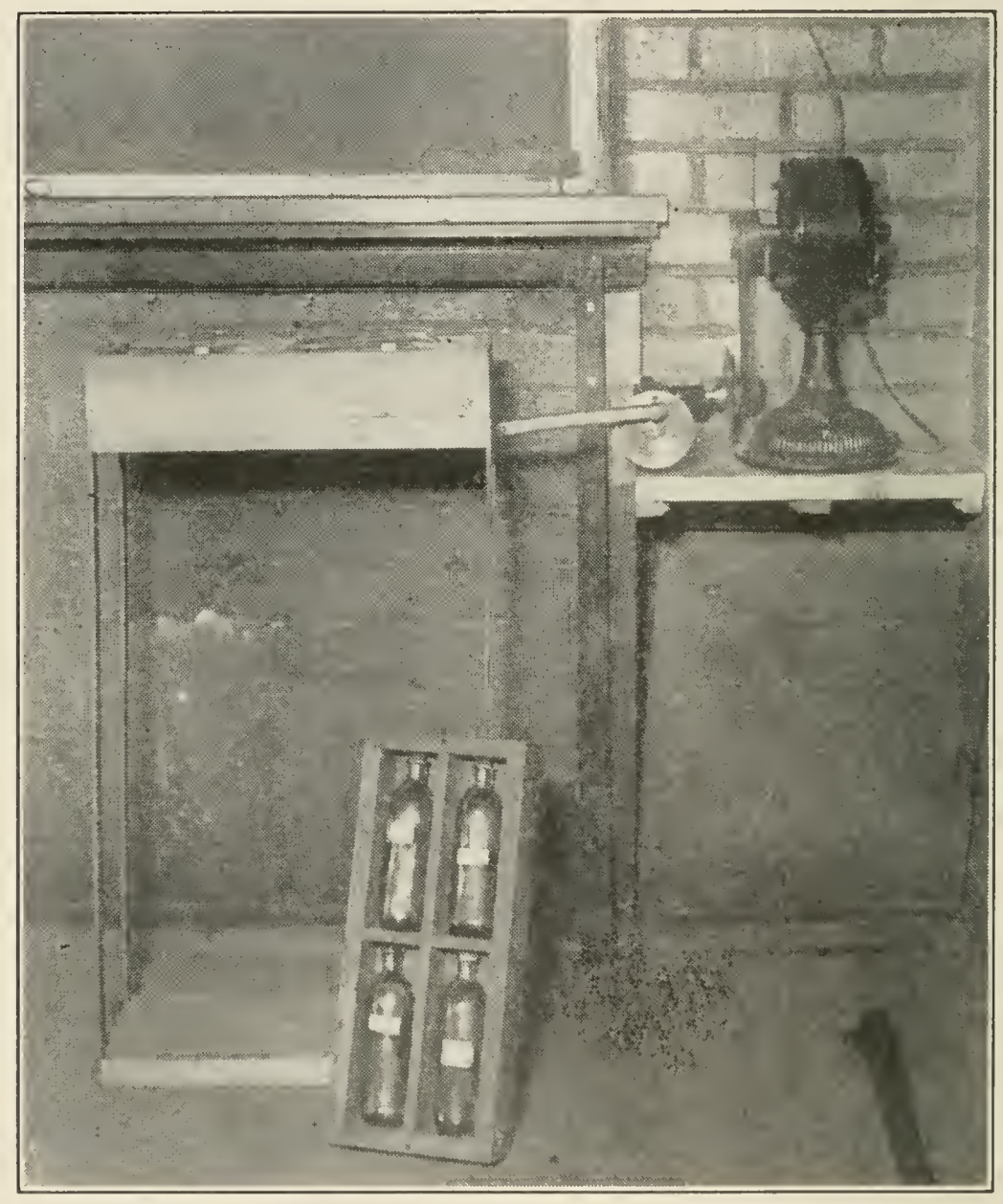

SHAKER USED IN THE PREPARATION OF SOIL SAMPLES FOR MECHANICAL ANALYSIS

mm.) have settled. Decant the liquid into a granite saucepan, stir up the soil remaining in the tube by means of a jet of distilled water, and again whirl for 
THE IHYSICAL IROPERTIES OF SOILS

STUDENT'S NOTES AND REPORT 
the same length of time. Again decant, and continue the process until the water becomes clear. Evaporate the liquid in the sancepan almost to dryness on a hot plate, and transfer the residue to a weighed porcelain dish. Complete the evaporation on a steam bath and dry in the oven, cool in a desiccator and weigh. This weight, less the weight of the dish, gives the amount of clay which should be expressed as per cent of the dry weight of the soil.

\section{SILT SEPARATIONS}

Stir up the soil remaining in the centrifugal tube and allow to stand for about one minute, or until all particles larger than silt (0.05) have settled. Decant the liquid into a saucepan, stir the remaining soil in the tube, and decant as before. Continue decanting at the proper time until the water is again clear. Evaporate the liquid in the saucepan as before, transfer the residue to a porcelain dish, dry, weigh, and calculate as in case of the clay.

\section{SAND SEPARATIONS}

Wash the sand remaining in the centrifugal tube into a porcelain dish, evaporate on the steam bath, dry in the oven, and weigh. This weight, less the weight of the dish, represents the total sands. Sift this sand through a nest of sieves provided for the purpose. The material remaining in the first sieve is the fine gravel; in the second, coarse sand; in the third, medium sand; in the fourth, fine sand; and in the fifth, very fine sand. Carefully transfer each grade of sand separately from the sieve to a dish and weigh.

Calculate the per cent of each grade, and tabulate 
TIIE PIIYSICAL PROIERTIES OF SOILS

STUDENT'S NOTES AND REPORT 
the results. Discuss the value of mechanical analysis as an indicator of the adaptability of soils to crops.

DETERMINATION OF THE LOSS ON IGNITION

Heat the dishes containing the oven-dry samples to dull redness, over a bunsen burner, until all of the organic matter is burned away. Allow to cool, and then moisten the mass with a few drops of ammonium carbonate. Heat slowly to about $150^{\circ} \mathrm{C}$., to drive off the excess of ammonia, cool in a desiccator and weigh.

The loss in weight of the sample represents the organic matter, volatile salts, and water of combination.

ReFEREnCES :

Burkett, "Soils," pp. 30-33.

Bureau of Soils, Bulletin No. 5 .

Bureau of Soils, Bulletin No. 24 . 
THE PHYSICAL PROPERTIES OF SOILS

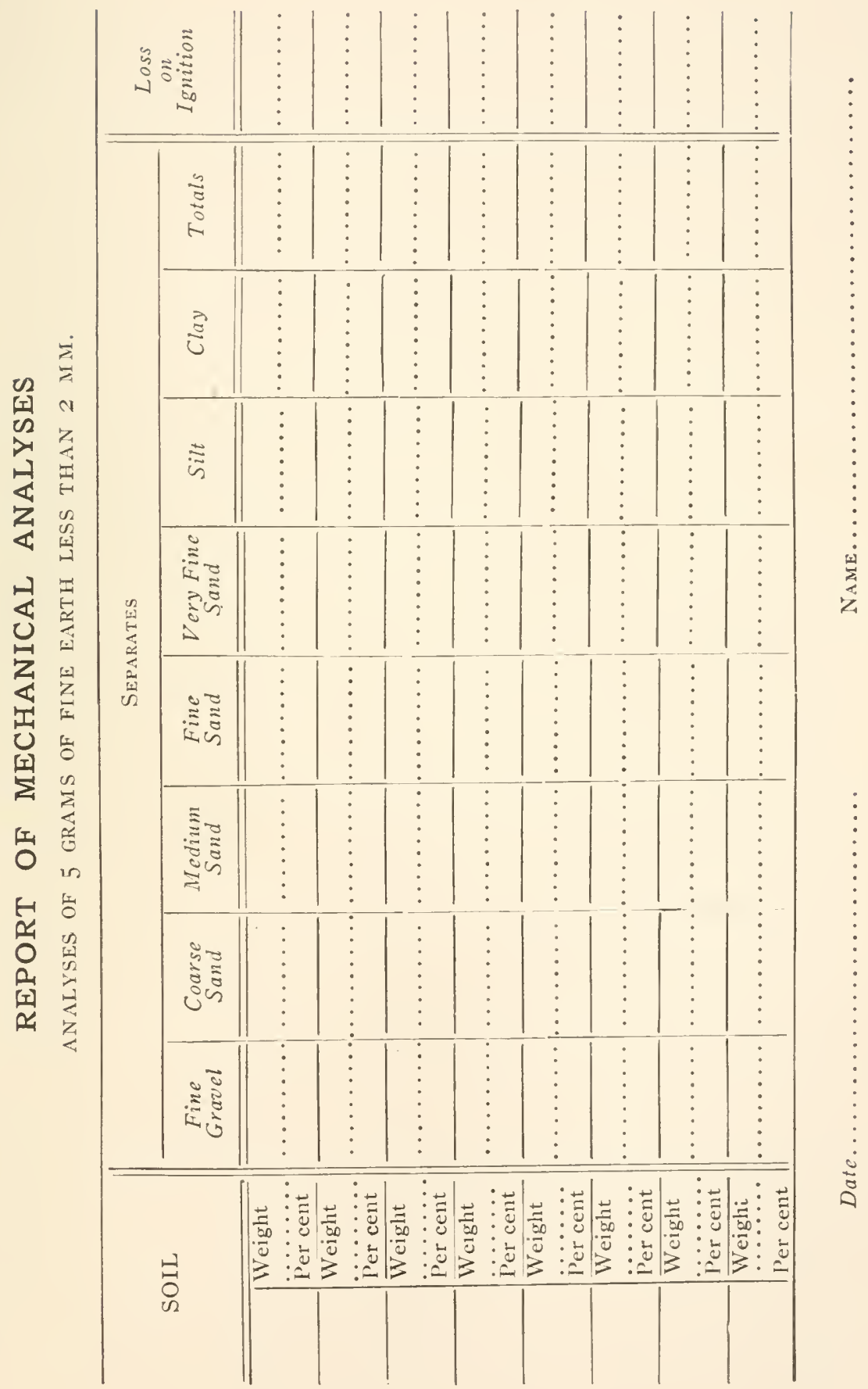




\section{EIGHTEENTH EXERCISE}

\section{CHROMIC ACID METHOD OF DETER- MINING ORGANIC MATTER}

MANy of the physical properties of soils are influenced by the amount of organic matter present. An accurate method for its determination is important, therefore, in the study of the physical properties of soils.

The determination of organic matter by dry combustion usually gives results that are too high, owing to the fact that combined water is driven off at the high temperature necessary for the complete combustion of the organic matter. The chromic acid, or wet combustion, method does not drive off this combined water, hence it is free from this objection.

\section{METIIOD OF DETERMINATION}

The apparatus $(\mathrm{T})$ consists of a round-bottomed flask of about $400 \mathrm{cc}$. capacity in which the combustion is effected. Connected to this flask is a train of absorption bulbs, so arranged that the $\mathrm{CO}_{z}$ produced by the breaking down of the organic matter is absorbed, and may be weighed at the close of the experiment.

A carefully weighed sample of soil of about ten grams is brought into the combustion flask, from five to ten grams of pulverized potassium bichromate is added, and the whole thoroughly mixed. The flask is closed, and a gentle stream of air is drawn through the entire system by means of an aspirator. After about ten minutes, concentrated sulplutric acid (sp. gr. about $\mathrm{I}_{83}$ ) is added by means of a dropping funnel.

The combustion flask is slowly heated until the acid begins to give off fumes. It is held at this temperature 
THE PHYSICAL PROPERTIES OF SOILS

93

STUDENT'S NOTES AND REPORT 
for about ten minutes or until the combustion of the organic matter is complete, and then allowed to cool. Care must be taken that a steady stream of air is kept passing through the system.

The amount of $\mathrm{CO}_{2}$ given off is determined by weighing the potash absorption bulb, and its acid guard bulb, at the beginning, and again at the close of the experiment. In calculating the per cent of organic

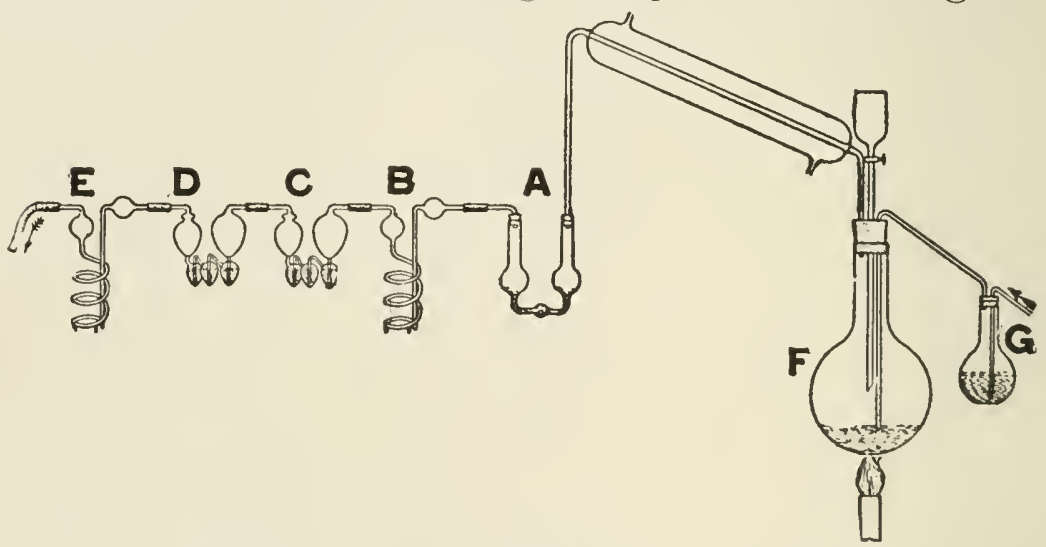

APPARATUS USED FOR THE DETERMINATION OF THE ORGANIC MATTER IN SOILS BY THE WET-COMBUSTION METHOD

(Bulletin No. 24, Bureau of Soils)

matter in the soil from the weight of $\mathrm{CO}_{2}$ found, it is necessary to use a conversion factor which, multiplied by the weight of the $\mathrm{CO}_{2}$, gives the weight of the organic matter from which the gas was derived. The factor generally accepted for this purpose is $0.47 \mathrm{r}$, based upon the investigations of Wollny and his study of the carbon content of the humus of soils.

Certain modifications of the above method are necessary when large quantities of chlorides and carbonates are present in the soil.

For a full description of the apparatus, and complete details of the method, the student is referred to Bulletin No. 24, Bureau of Soils. 


\section{STUDENT'S NOTES AND REPORT}




\section{A P P EN DIX}

\section{DIRECTIONS FOR TAKING SOIL SAMPLES}

In securing samples of soil from the field for analysis or for the determination of moisture content or pore space, great care must be taken to have the

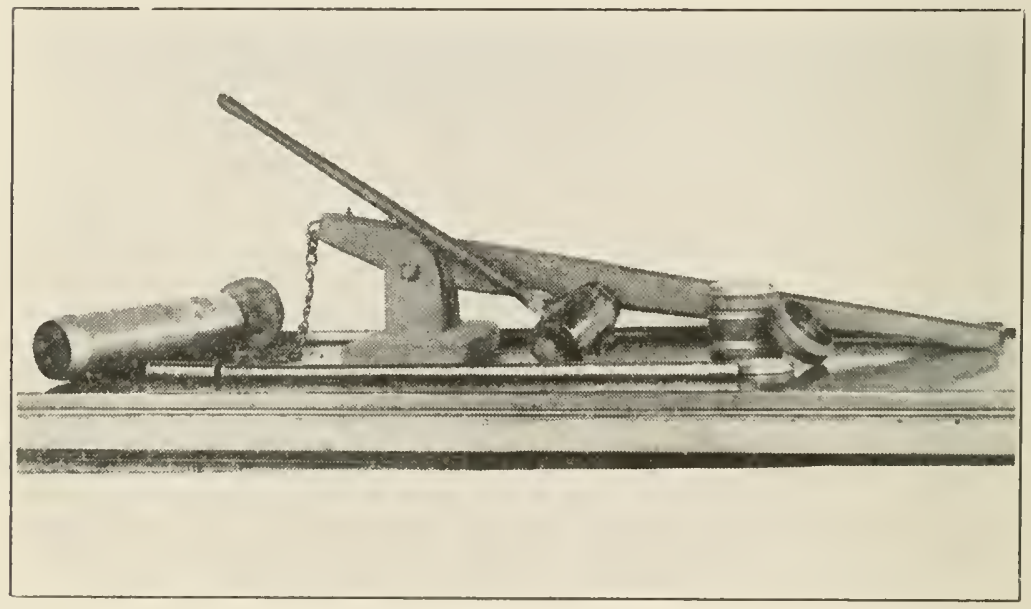

SAMPLING APPARATUS

Used for taking samples when a large quantity of soil is desired. The sampling tube is 4 inclies in diameter and 15 inches long

samples represent, as nearly as possible, average field conclitions. When taken for laboratory use the sample should be representative of the soil type, or of the field conditions which are under consideration.

Soils of glacial origin are quite variable in composition, making it extremely difficult to secure a sample that will accurately represent any definite area or a particular soil type. Soils of residual origin are much less variable in composition. 
THE PIISICIL PROPERTIES OF SOILS

STUDENT'S NOTES AND REPORT

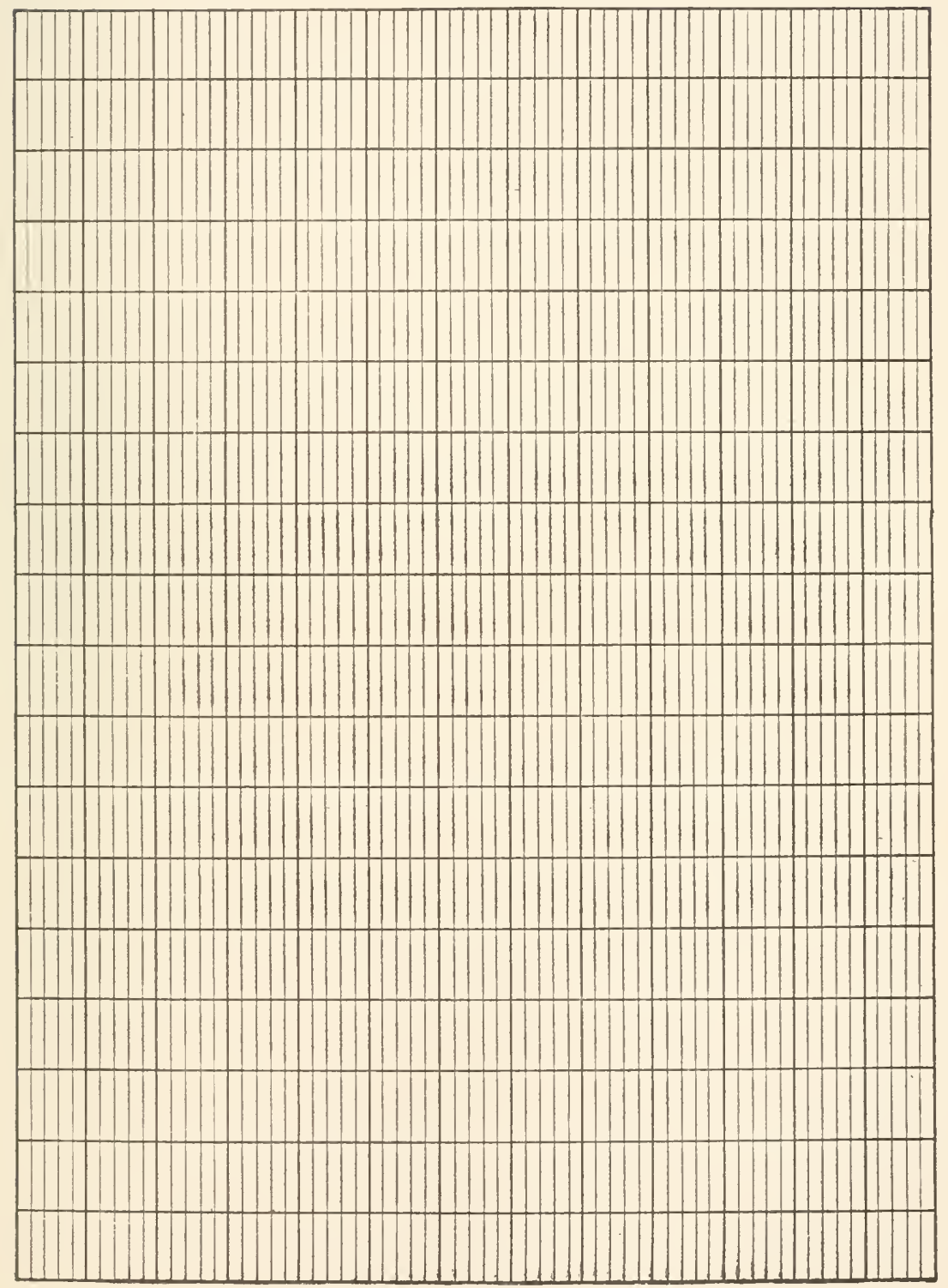

PLAIN CO-ORDINATE PAPER 
In order to secure a sample that will be representative of a given field or plot it is necessary to drive down a sampling tube in a number of places and combine the cores into a composite sample. A moisture determination made in duplicate on this composite sample may be taken to represent the average moisture of the soil over the field under observation.

Samples taken for mechanical analysis should be

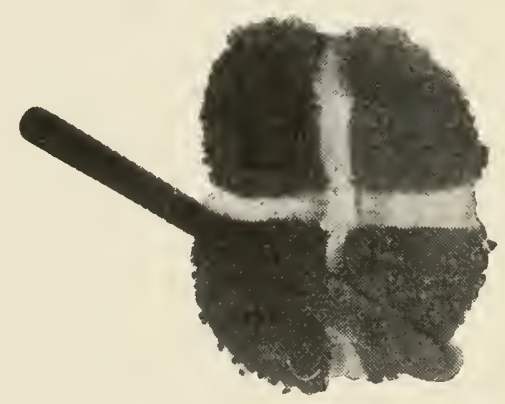

METHOD OF SUB-SAMPLING SOIL BY SUCCESSIVE DIVISIONS OF THE MAIN SAMPLE

dried, thoroughly mixed, and the lumps broken with a rolling-pin. They should then be passed through a $2 \mathrm{~mm}$. sieve to remove the gravel and sticks. The portion of the sample passing through the sieve is spread out on a piece of heavy paper and thoroughly mixed with a large spatula. The sample is then divided into four parts and one portion is again thoroughly mixed. A twenty or thirty gram sample is taken from this fine material, dried in the oven and used for the analysis.

The method of taking the sample and its subsequent treatment will vary with the purpose for which the sample is taken. 
References :

Stevenson \& Schaub, "Soil Physics Laboratory Guide."

Bulletin No. I6, Bureau of Soils, pp. I3-I 5 .

Bulletin No. 24, Bureau of Soils, p. 9.

\section{STANDARDIZATION OF THE EYE-PIECE MICROMETER}

THE microscope used in the mechanical analysis of soils must be provided with an eye-piece micrometer for measuring the diameter of the soil grains composing the different separates. The value of the divisions on this eye-piece micrometer will vary with the different magnifying powers of the microscope. It becomes necessary, therefore, to determine the value of the divisions in the eye-piece by comparison with a standard of known value placed on the stage of the microscope. This is done by comparing the eye-piece with a stage micrometer of known value, and computing the value of one division on the eye-piece micrometer for each optical combination. When this is known, the number of spaces which the soil particles must cover to belong to a given grade is determined by dividing the diameter of the particles by the value of one space.

Each student is required to make a standardization and compute the value of the divisions of the eye-piece for all of the combinations of the microscope used in the laboratory. The results must be tabulated and kept in this book for reference. 


\section{TABLE OF DATA}

I cc. of water $=$ I gram.

I cu. ft. of water $=62.25$ lbs. avoirdupois.

I gram $=0.0022$ lbs. avoirdupois.

I cc. $=0.06$ I cur. in.

I gal. $=23$ I cu. in.

I oz. avoirdupois $=28.35$ grams.

I kilogram $=2.20$ lbs. avoirclupois.

I inch $=25.4 \mathrm{~mm}$. 


\section{N D E X}

Air in field soils.

PAGE

Analysis of soils

Capillary water, its distribution.

44

So

rise of moisture

40

rise of moisture interrupted

moisture, continuous rise.

moisture, lateral movement

Clay separation .

Fertilizers retained in soils . . . . . . . . . 70

Flow of air in soils . . . . . . . . . . . 42

Hygroscopic moisture . . . . . . . . . Io in the field. . . . . . . . . . . . . . I2

Laboratory desk outfit . . . . . . . . . . 3

Lime flocculates soils . . . . . . . . . . 68

Lime and clay soils . . . . . . . . . . . 68

Mechanical analysis of soils . . . . . . . . . 6 bottle method. . . . . . . . . . . . . So centrifugal method . . . . . . . . . . 84

Mulches, effect of, on evaporation . . . . . . . 60 Evaporation controlled by . . . . . . . . 60

Absorptive power of . . . . . . . . 64

Organic matter . . . . . . . . . . . . . 90

Report on . . . . . . . . . . . . 9I

Determination of . . . . . . . . . . . . 92

Percolation of water . . . . . . . . . . 32

Pore space, determination of . . . . . . . . . 26

Calculation of . . . . . . . . . . 28

Physical properties of soils . . . . . . . . . 1

Sand . . . . . . . . . 88

Silt . . . . . . . . . . . . 88

Soil samples . . . . . . . . . . . . . . 96

Directions for taking . . . . . . . . . . . 96

Apparatus for sampling . . . . . . . . . . . 96

Eye-piece micrometer . . . . . . . . . . 99 
Specific gravity . . . . . . . . . . . . .

Calculation of . . . . . . . . . . . . 18

Method of determination . . . . . . . . I8

Spccific heat. . . . . . . . . . . . 74

in soils. . . . . . . . . . . . . . 74

Determination of . . . . . . . . . . . 74

Stock soils . . . . . . . . . . . . . 5

Volume weight . . . . . . . . . . . . 22

Calculation of . . . . . . . . . . . . . 26

Method to determine . . . . . . . . . . 22

Water-holding capacity . . . . . . . . . 38

Apparatus to determine . . . . . . . . 38 


\title{
STANDARD BOOKS
}

PUBLISHED BY

\section{ORANGE IUDD COMPANY}

\author{
NEW YORK \\ 139-441 Lafayette Street
}

\author{
CHICAGO \\ Marquette Building
}

\begin{abstract}
BOOKS sent to all parts of the world for catalog price Discounts for large quantities on applicatio. Carrespondence invited. Brief descriptive catalog free. Large illustrated catalog, six cents.
\end{abstract}

\section{Soils}

By Charles William Burkett, Director Kansas Agricultural Experiment Station. The most complete and popular work of the kind ever published. As a rule, a book of this sort is dry and uninteresting, but in this case it reads like a novel. The author has put into it his individuality. The story of the properties of the soils, their improvement and management, as well as a discussion of the problems of crop growing and crop feeding, make this book equally valuable to the farmer, student and teacher.

There are many illustrations of a practical character, each one suggesting some fundamental principle in soil manage. ment. 303 pages. $5^{1 / 2} \times 8$ inches. Cloth. . . . \$1.25

\section{Insects Injurious to Vegetables}

By Dr. F. H. Chittenden, of the United States Department of Agriculture. A complete, practical work giving descriptions of the more important insects attacking vegetables of all kinds with simple and inexpensive remedies to check and destroy them, together with timely suggestions to prevent their recurrence. A ready reference book for truckers, marketgardeners, farmers as well as others who grow vegetables in a small way for home use; a valuable guide for college and experiment station workers, school-teachers and others interested in entomology of nature study. Profusely illustrated. $5 \frac{1}{2} \times 8$ inches. 300 pages. Cloth. . .". . . \$I.50 


\section{The Cereals in America}

By Thontas F. Hunt, M.S., D.Agri., Professor of Agronomy, Cornell University. If you raise five acres of any kind of grain you cannot afford to be without this book. It is in every way the best book on the sulpject that has ever been written. It treats of the cultivation and improvement of every grain crop raised in America in a thoroughly practical and accurate manner. 'The subject-matter includes a comprehensive and succinct treatise of wheat, maize, oats, barley, rye, rice, sorghum (kafir corn) and buckwheat, as related particularly to American conditions. First-hand knowledge lias been the policy of the author in his work, and every crop treated is presented in the light of individual study of the plant. If you have this book you have the latest and best that has beer written upon the subject. Illustrated. 450 pages. $5 \frac{1}{2} \times 8$ inches. Cloth. . . . . . . . . . . . \$I.75

\section{The Forage and Fiber Crops in America}

By Thomas F. Hunt. This book is exactly what its title indicates. It is indispensable to the farmer, student and teacher who wishes all the latest and most important information on the subject of forage and fiber crops. Like its famous companion, "The Cereals in America," by the same author, it treats of the cultivation and improvement of every one of the forage and fiber crops. With this book in hand, you have the latest and most up-to-date information available. Illustrated. 428 pages. 5 I /2 $\times 8$ inches. Cloth. . . . \$1.75

\section{The Book of Alfalfa}

History. Cultivation and Merits. Its Uses as a Forage and Fertilizer. The appearance of the Hon. F. D. Coburn's little book on Alfalfa a few years agn has been a profit revelation to thousands of farmers throughont the country, and the increasing demand for still more information on the subject has induced the anthor to prepare the present volume. which is by far the most authoritative, complete and valuable work on this forage crop pulblished anywhere. It is printed on fine paper and illustrited with many full-page photographs that were taken with the especial view of their relation to the text. 336 pages. $6 r / 2 \times 9$ inches. Bonnd in cloth, with gold stamping. It is unquestionably the handsomest agricultural reference book that has ever been issued. Price, postpaid . . \$ \$2.00

\section{Clean Milk}

Bv S. D. Bercher, M.D. In thic bonk the author sets forth practical methods for the exclusion of hacteria from milk, and how to prevent contanination of milk from the stable to the consumer. Illustrated. 5 x 7 inches. 146 pages. Cloth. 


YB 51434 
